\title{
Correlation of Middle and Upper Devonian shales in the
}

Marcellus-producing regions of Pennsylvania

\author{
John A. Harper ${ }^{1}$, Robin V. Anthony ${ }^{2}$, Kristin M. Carter², \\ Katherine W. Schmid ${ }^{2}$, Brian J. Dunst ${ }^{2}$, Michele L. Cooney ${ }^{3}$
}

1PA DCNR, Bureau of Topographic \& Geologic Survey (ret.) 2PA DCNR, Bureau of Topographic \& Geologic Survey

${ }^{3} \mathrm{AECOM}$ 


\section{Introduction and Purpose}

- Introduce MRCSP regional characterization efforts

- Present a cursory history of shale geology in the Appalachian basin

- Explain current interpretive methods as applied to Pennsylvania data

- Provide current lithostratigraphic correlations 


\section{Midwest Regional Carbon Sequestration Partnership}

- What is it?

- Three phases

- Current regional characterization work

- Support for CCUS

Carbon Capture Utilization \& Storage

- EOR/EGR

Enhanced Oil/Gas Recovery

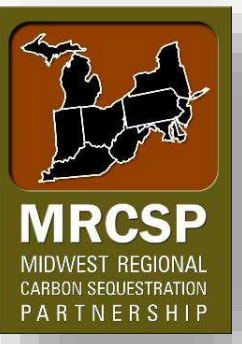




\section{Appalachian Basin Shale Work}

- Eastern Gas Shales Project (EGSP) correlation based on GR, "Marcellus facies" vs. Marcellus Formation

- Modern Marcellus shale play (2004) thousands of wells with modern geophysical logs

- Technology and data availability give rise to improved lithostratigraphic interpretations 


\section{EGSP Approach}
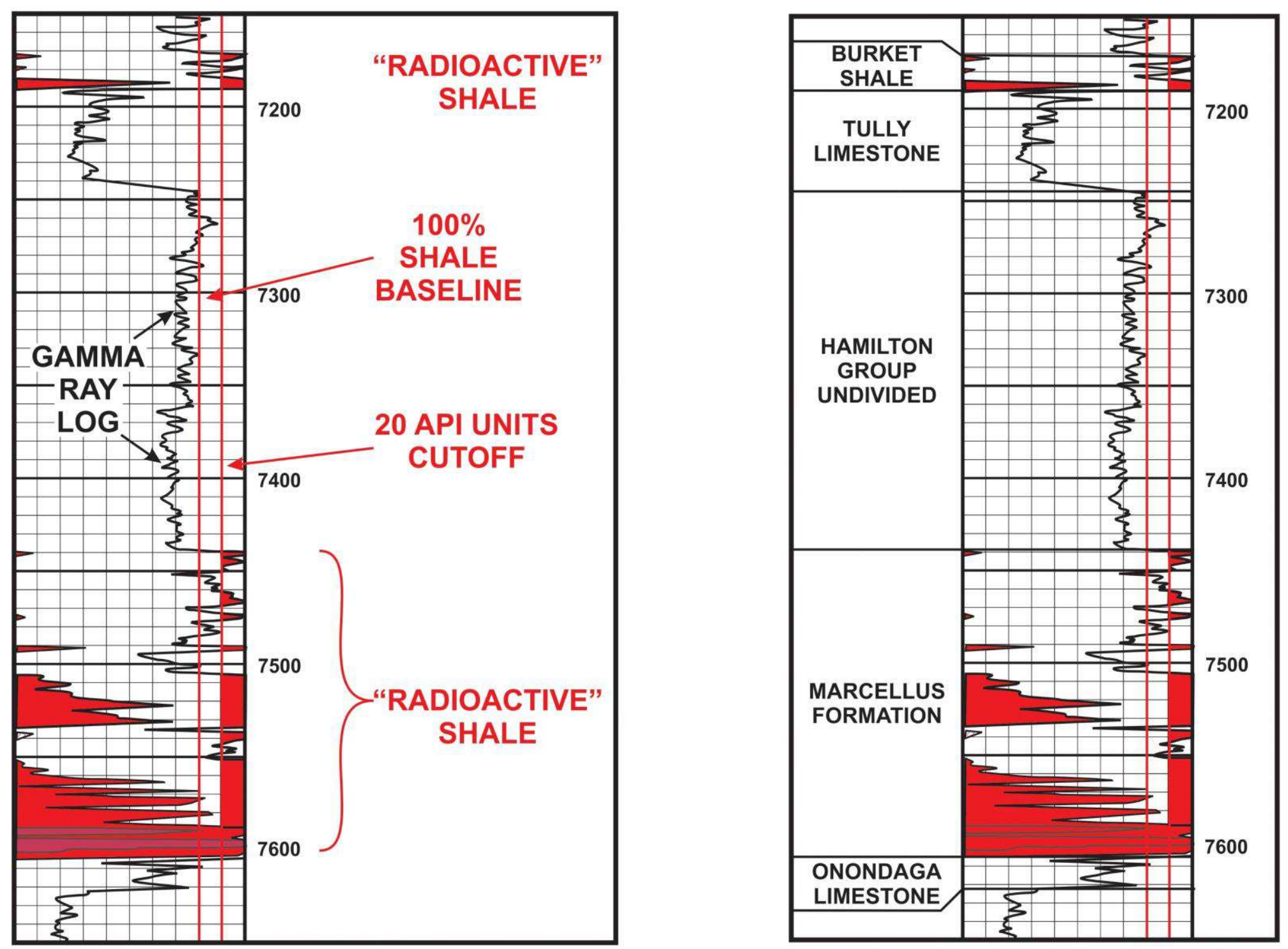

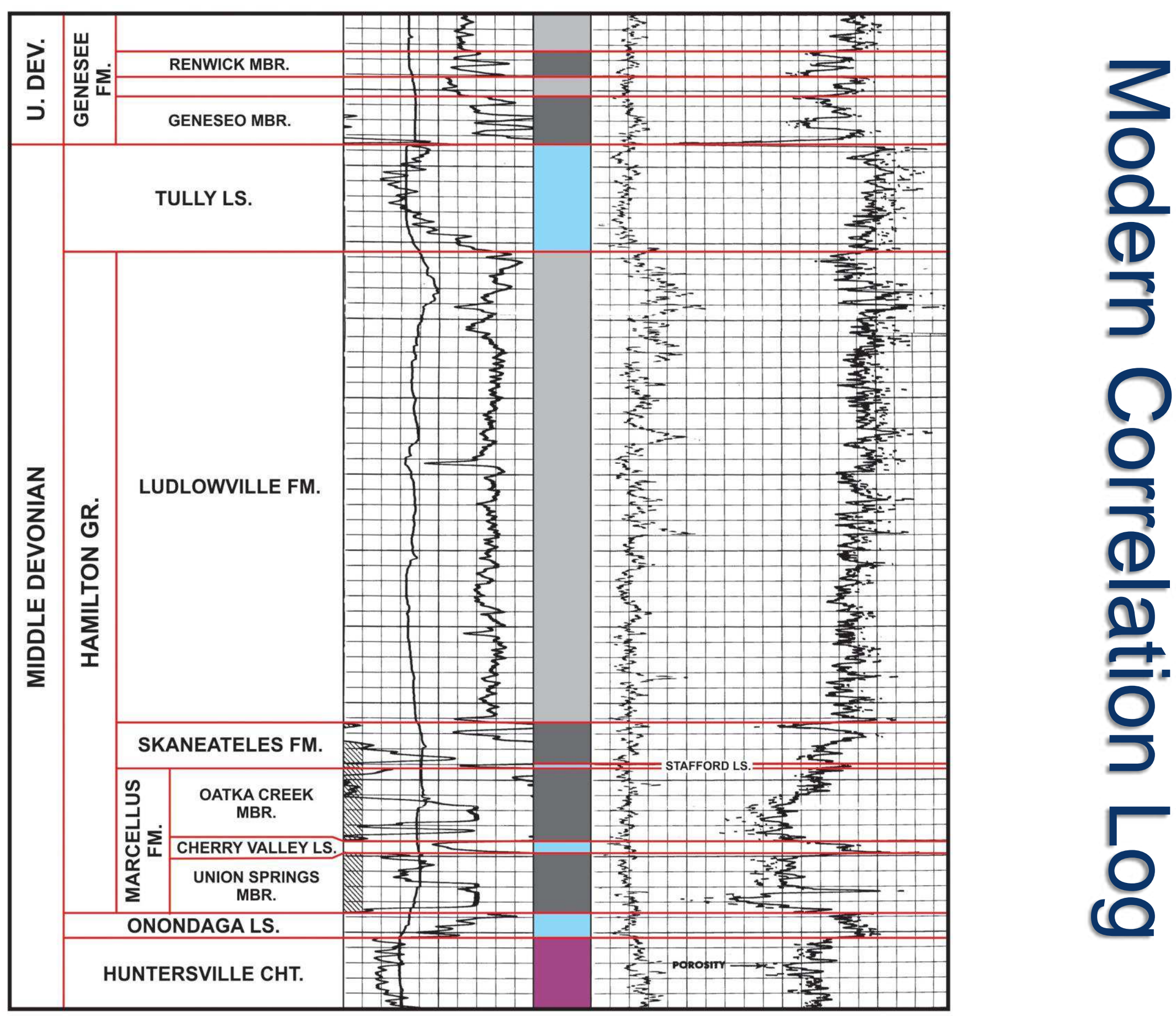


\section{Methods}

- Regional mapping

using geophysical log control for

3,500 wells in 41 Pennsylvania counties

- Geologic cross sections

using New York terminology

- Integration of regional structural controls

- Resolution of correlations to formation and/or member level

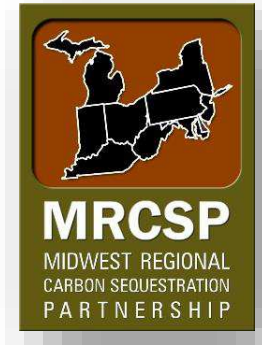




\section{Stratigraphic Correlation Diagram}

- Rhinestreet

- Middlesex

- Geneseo-Burket

- Marcellus

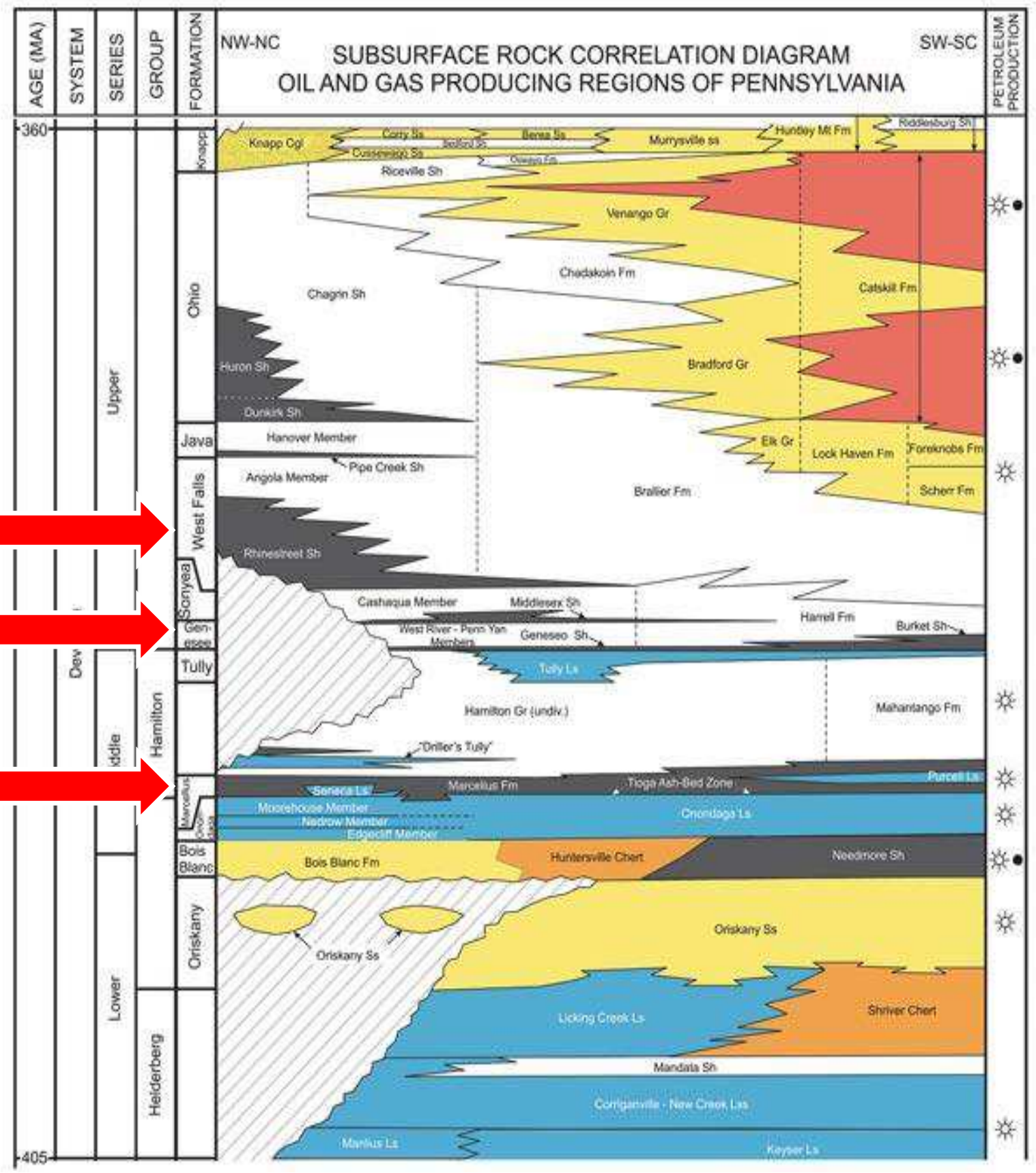

Carter, 2007 


\section{Devonian shale lithostratigraphy}

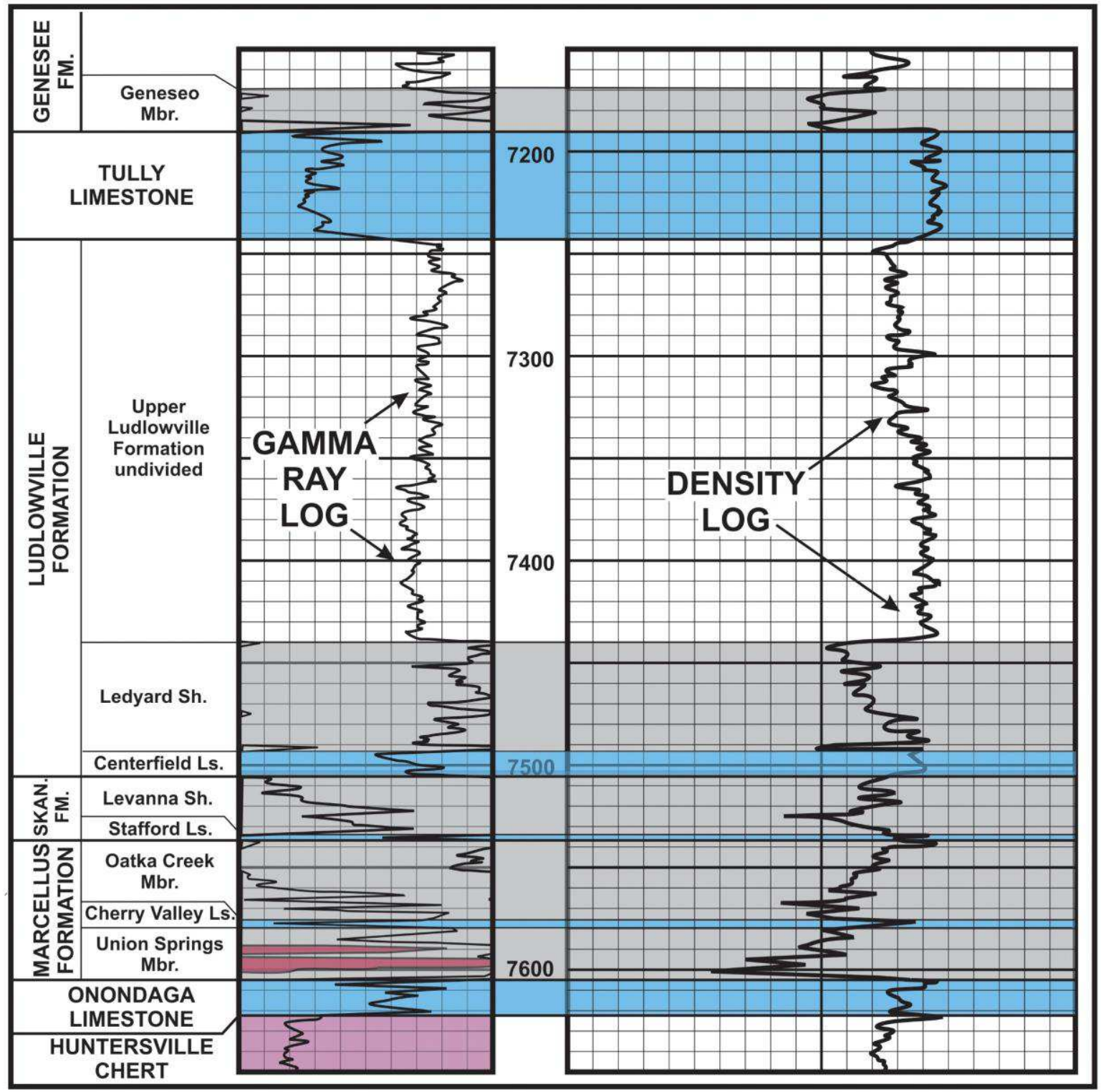




\section{Cross Section Location Map}

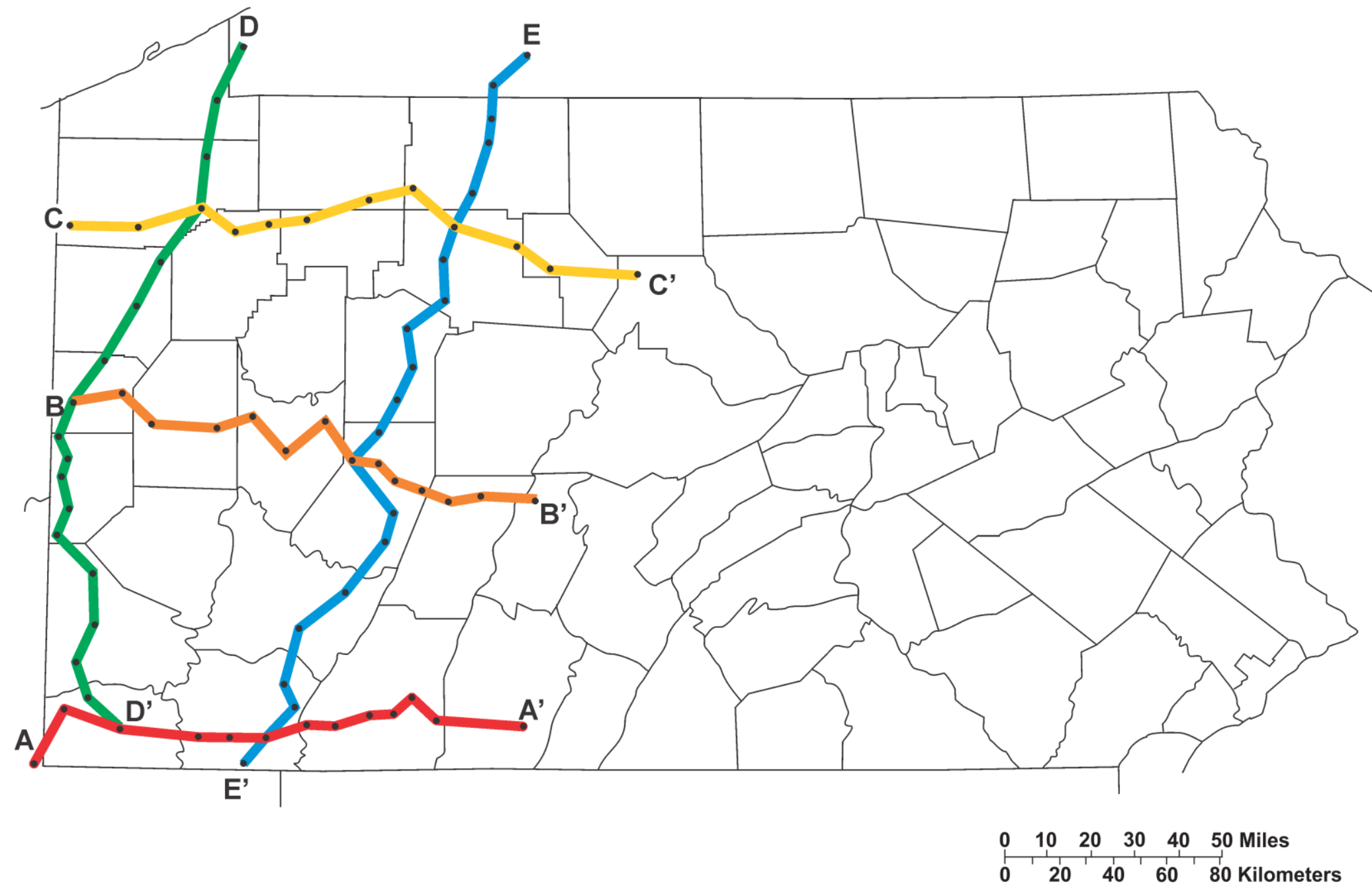




\section{Cross Section Location Map}

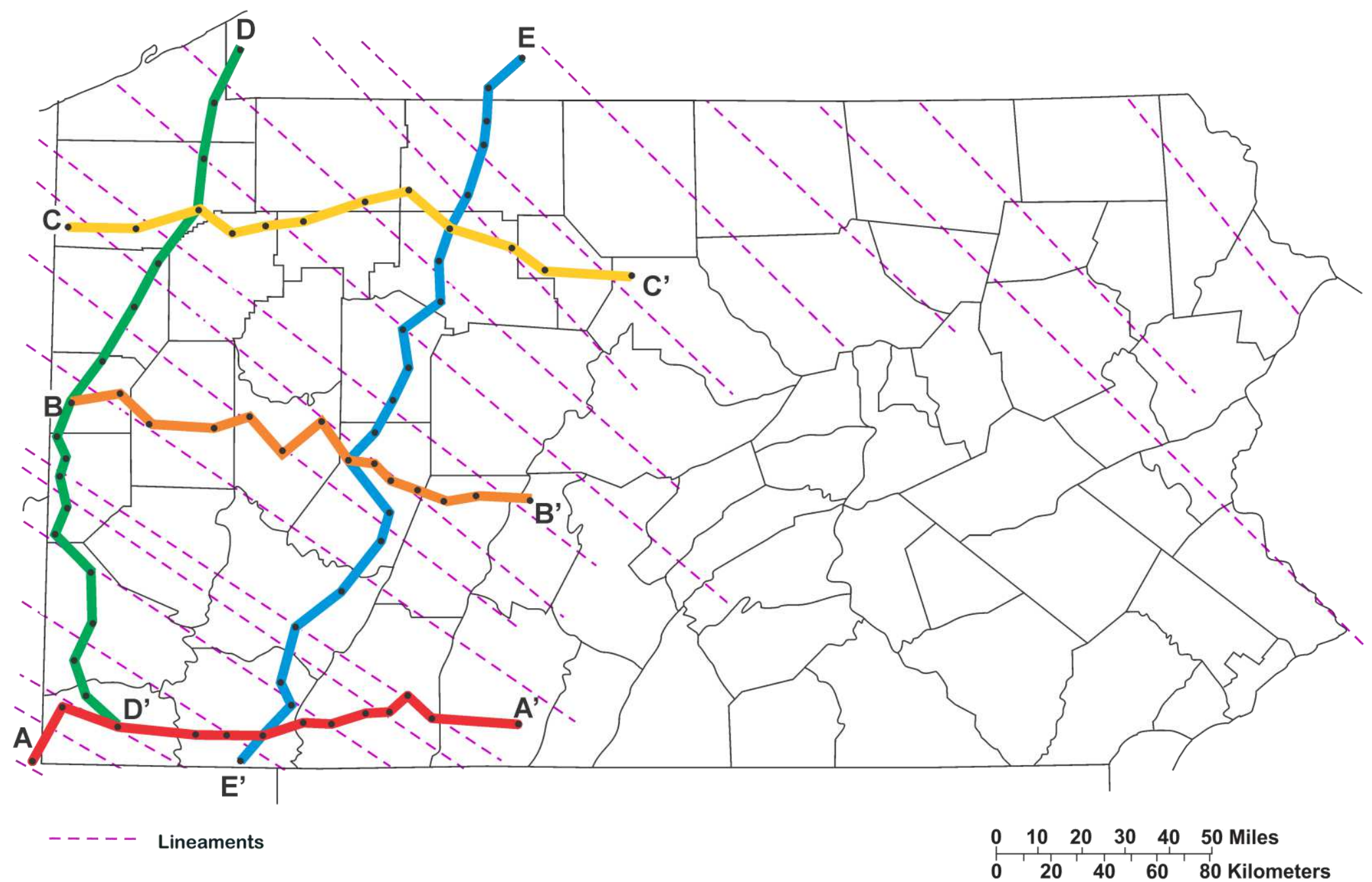




\section{NE-SW Cross Section (Basin Strike)}

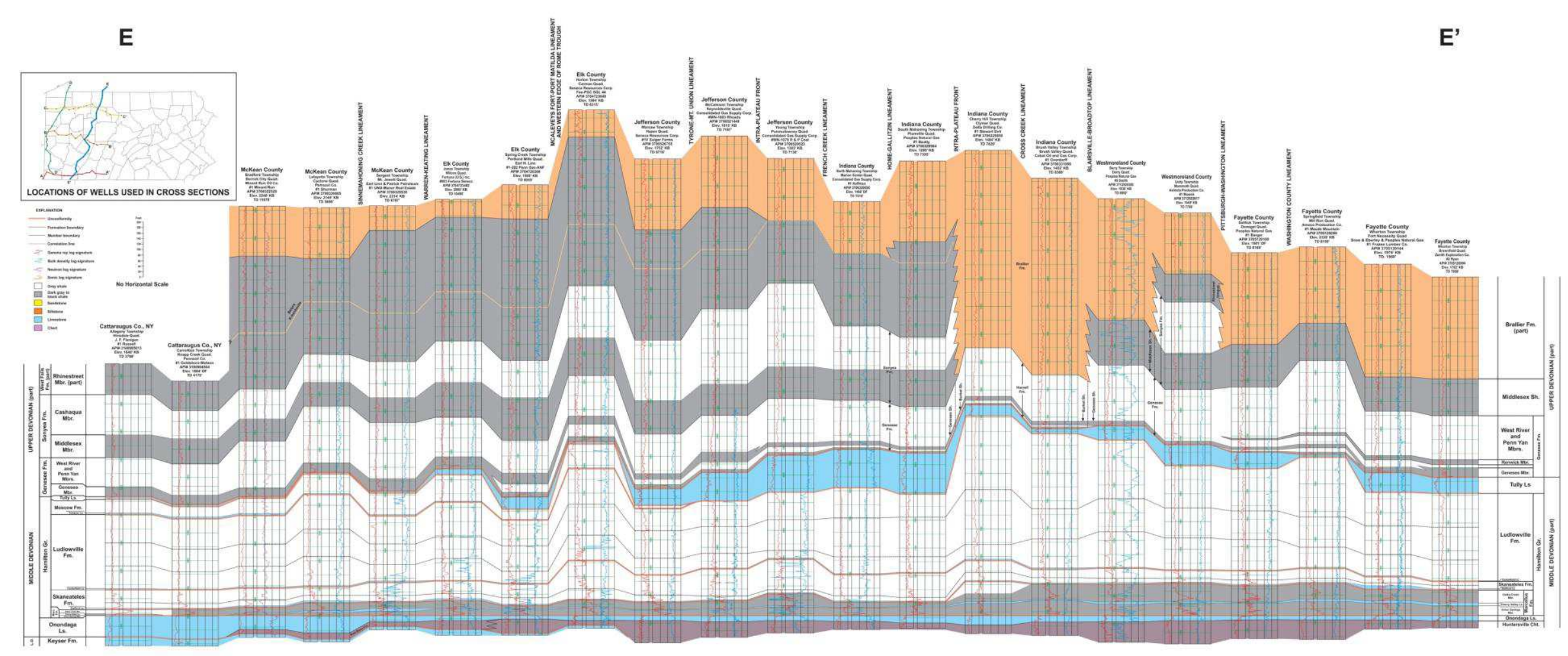

CROSS SECTION E-E': STRATIGRAPHIC CORRELATION OF MIDDLE AND UPPER DEVONIAN SHALES FROM CATTARAUGUS COUNTY, NY TO FAYETTE COUNTY, PA 


\section{W-E Cross Section (Basin Dip)}

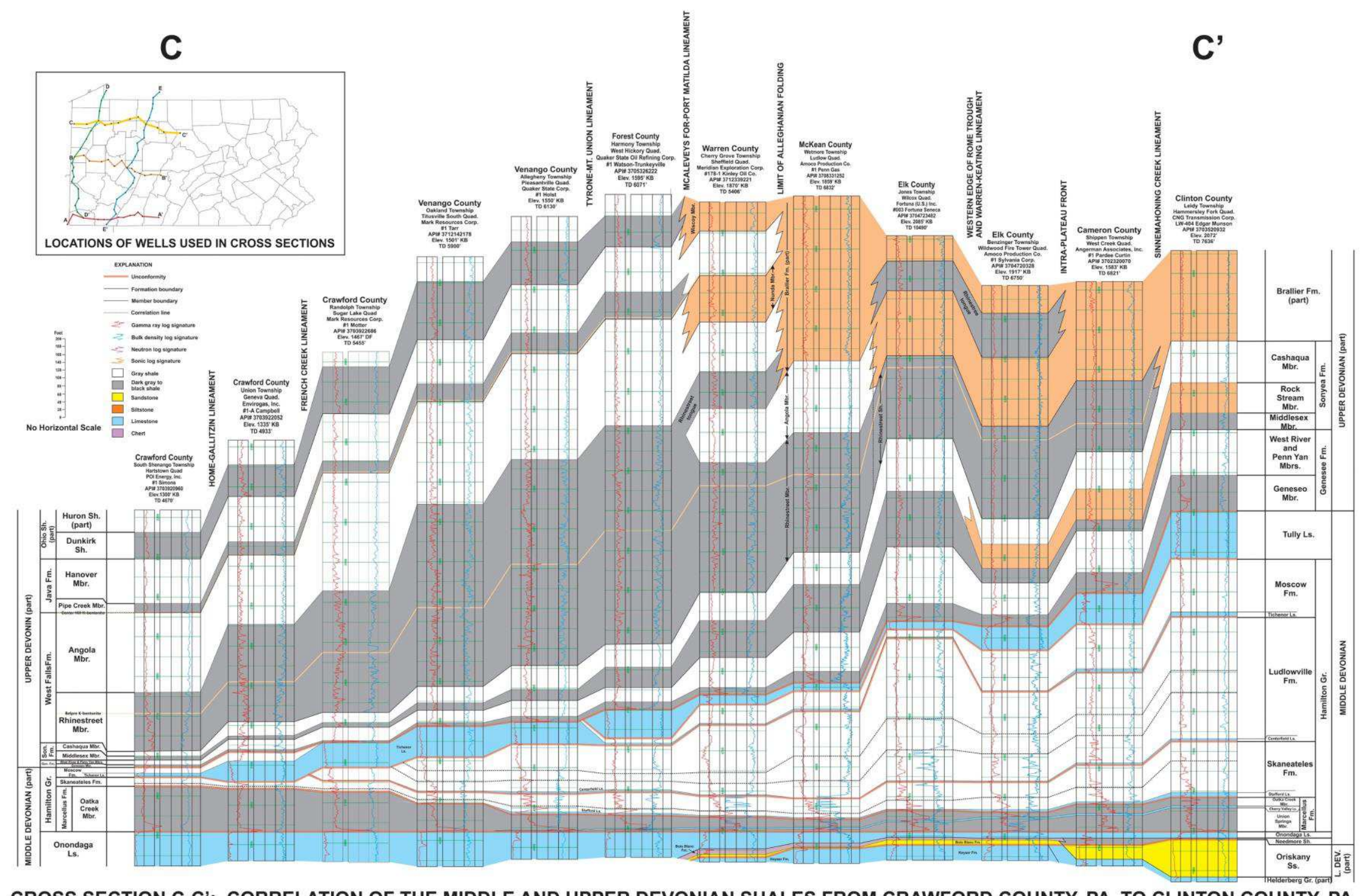




\section{Marcellus Shale}
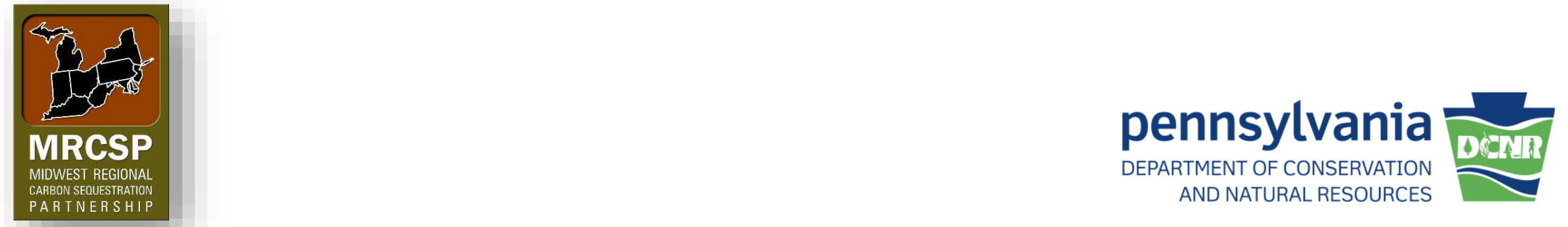


\section{Marcellus Structure Map}

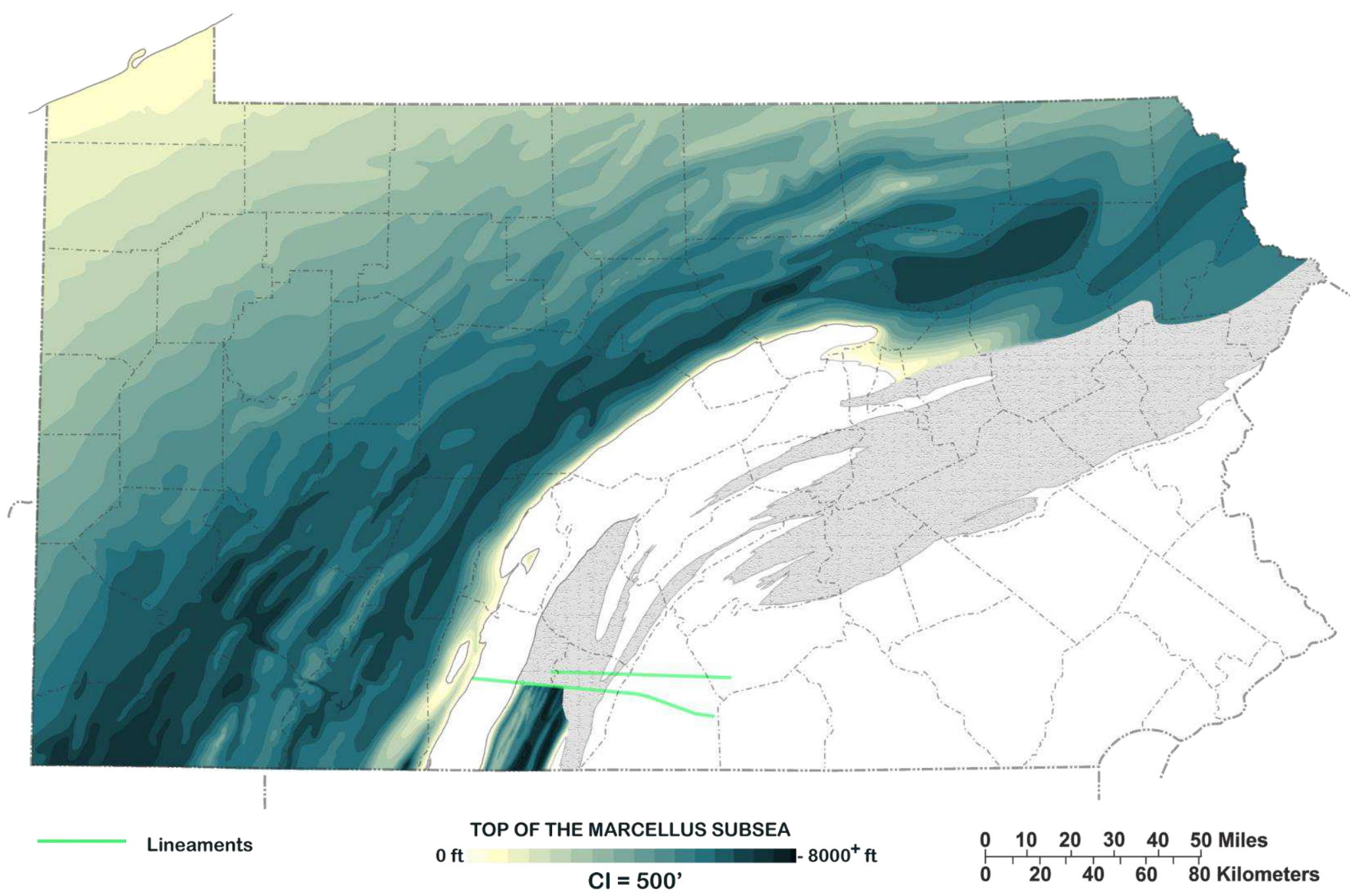




\section{Major Lineaments}

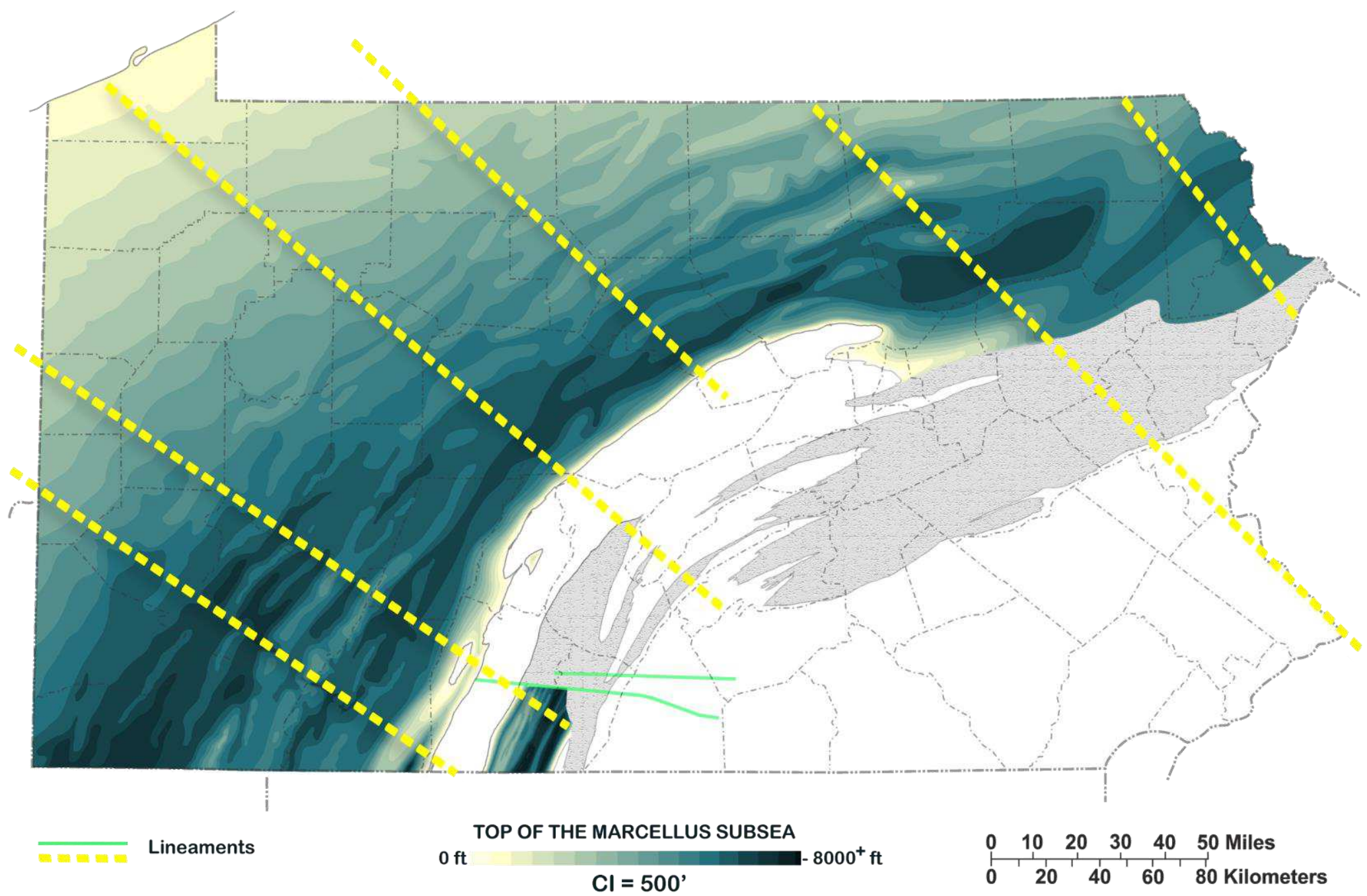




\section{Marcellus Structure Map with Lineaments}

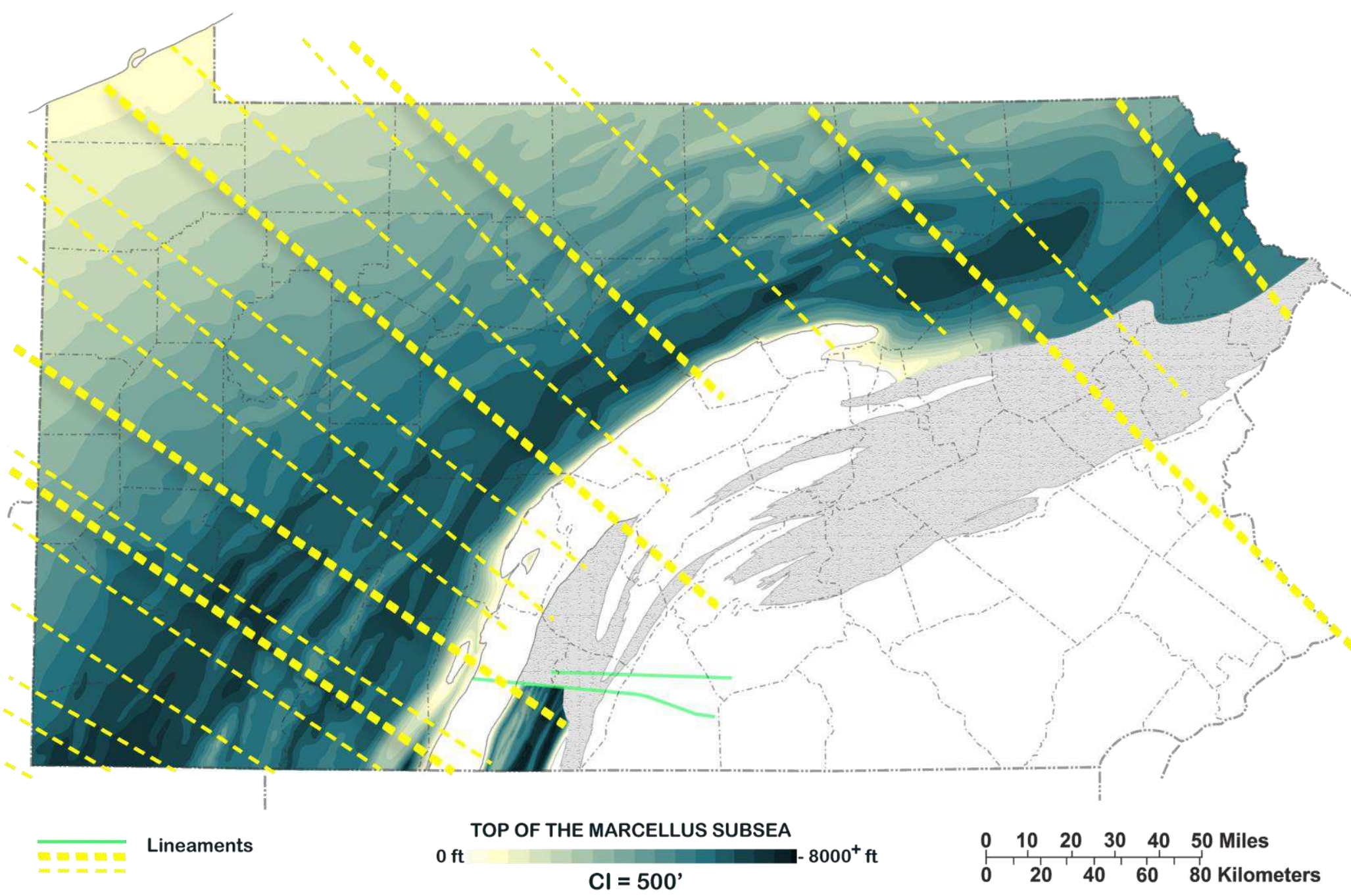




\section{Marcellus}

\section{Cross-section Inset 1 along E-E'}

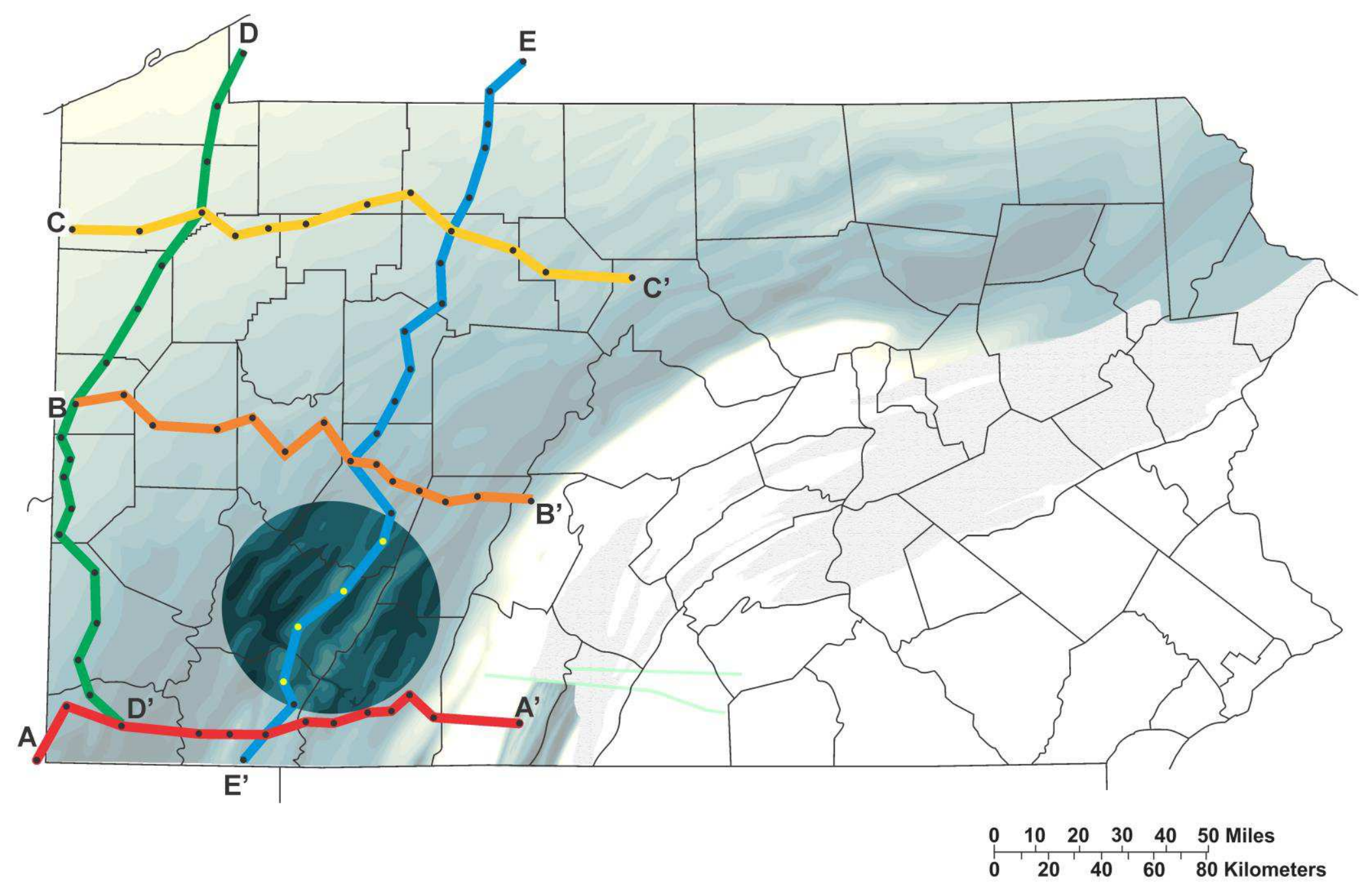




\section{Marcellus}

\section{Cross-section Inset 1 along E-E'}

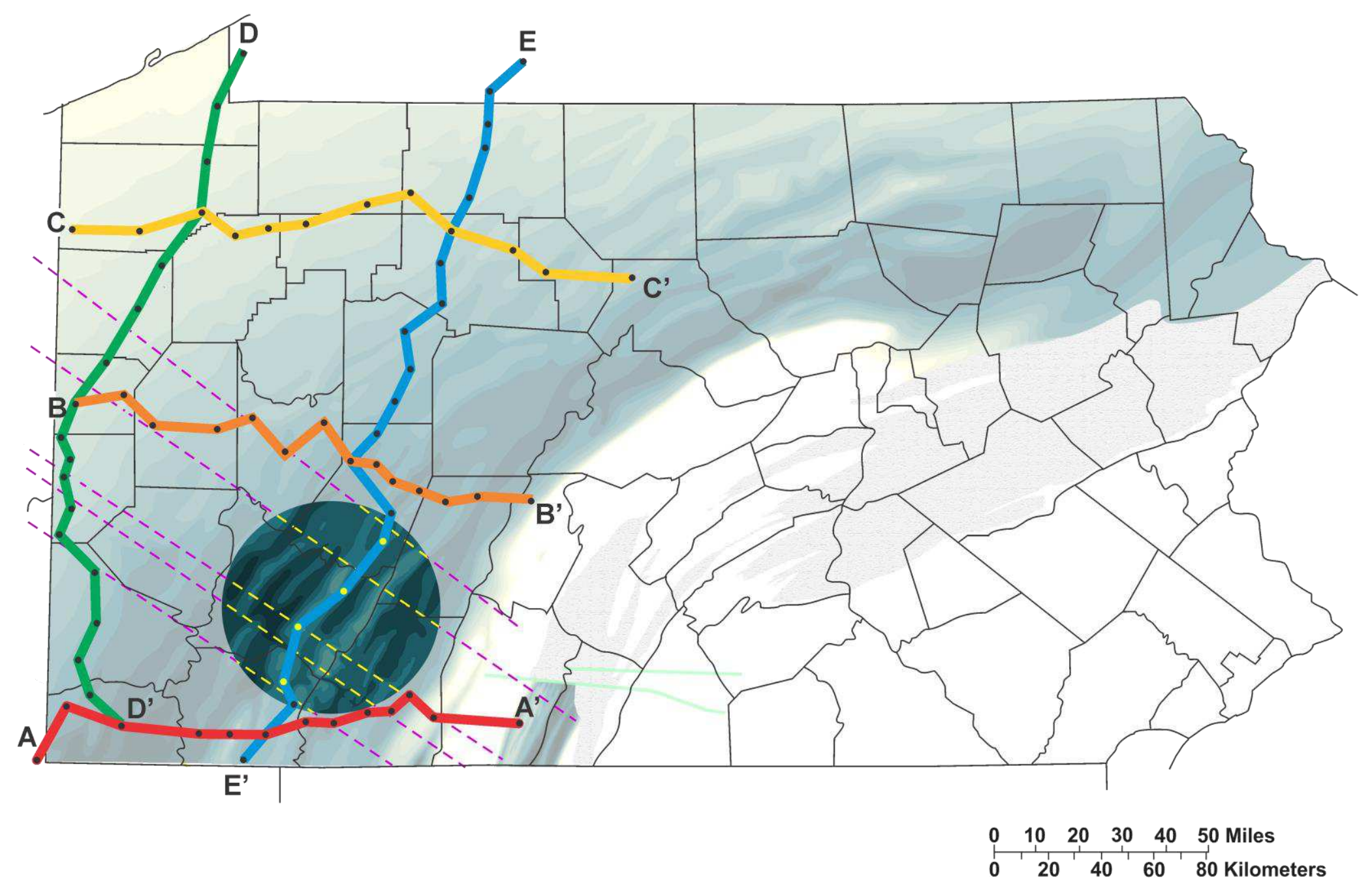




\section{Marcellus}

\section{Cross-section inset 2 along D-D'}

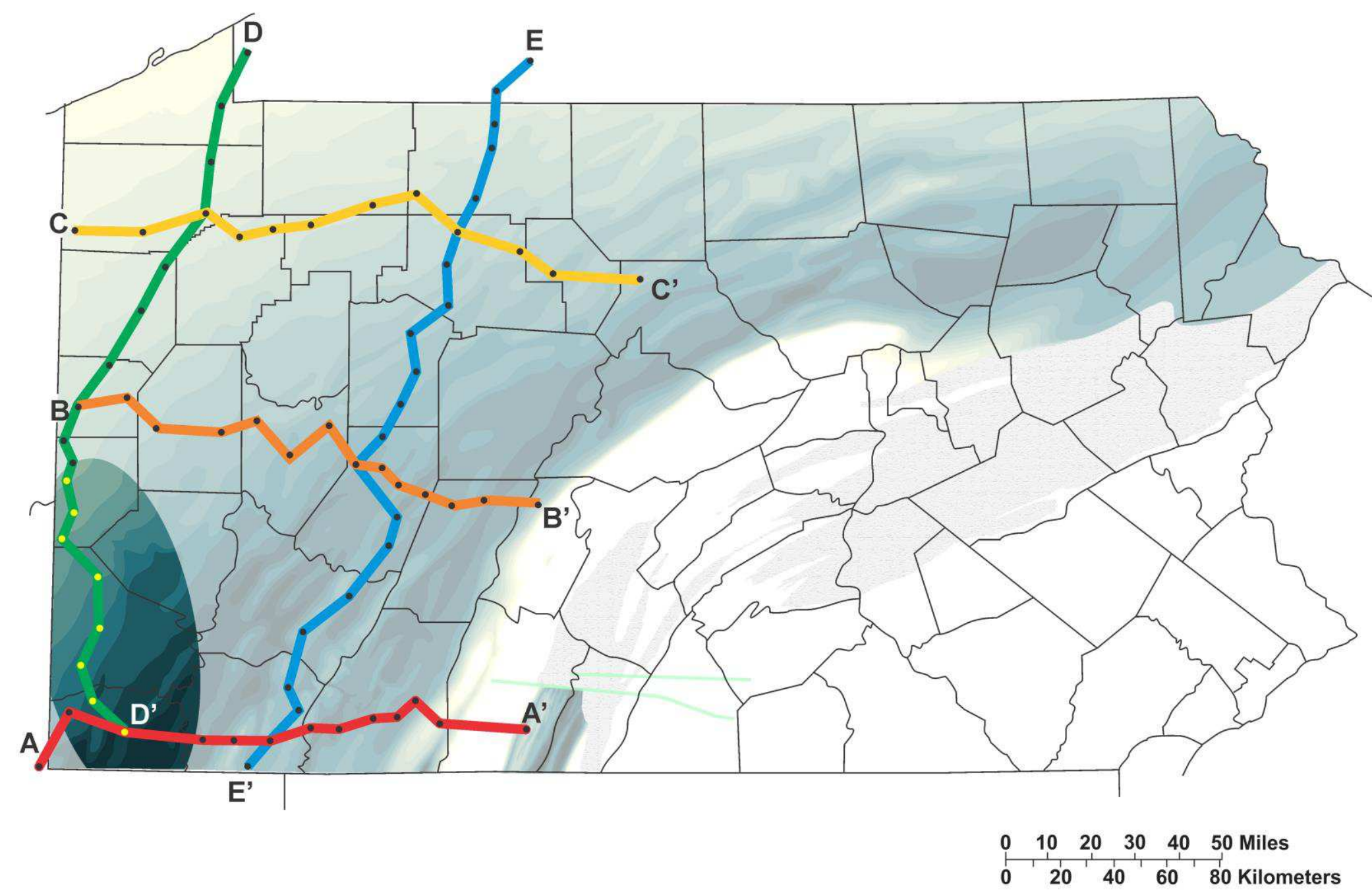




\section{Marcellus}

\section{Cross-section inset 2 along D-D'}

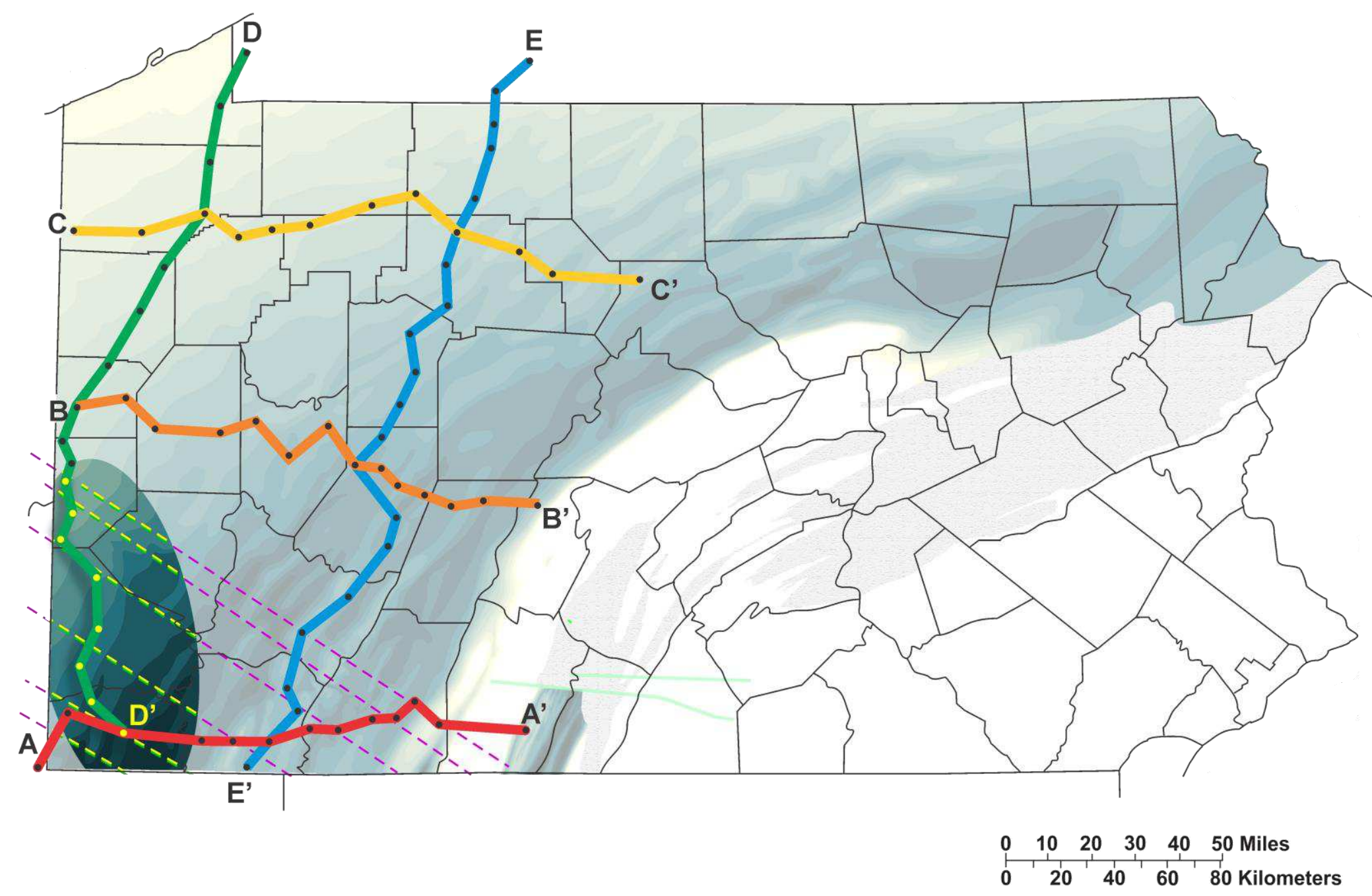




\section{Marcellus}

\section{Cross-section inset 2 along D-D'}

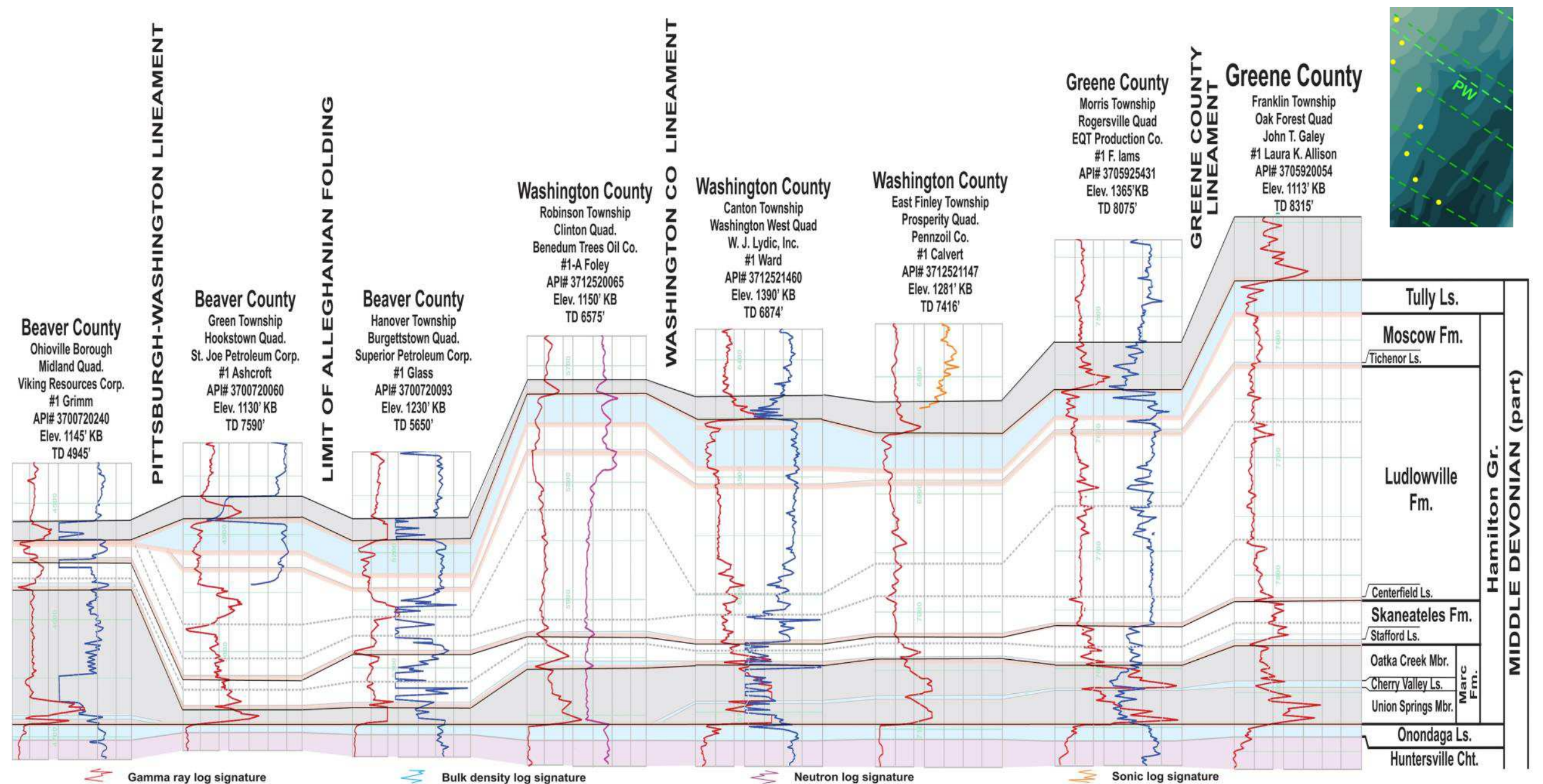




\section{Geneseo and Burket Shales}
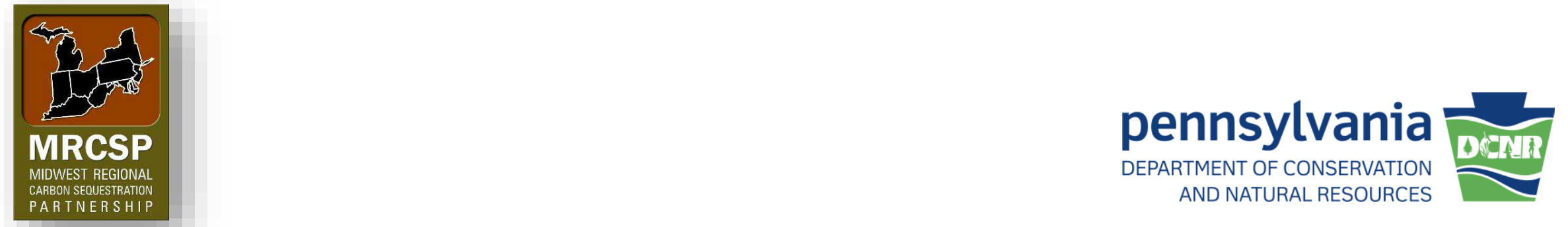


\section{Measured Depth to Top of Geneseo / Burket}

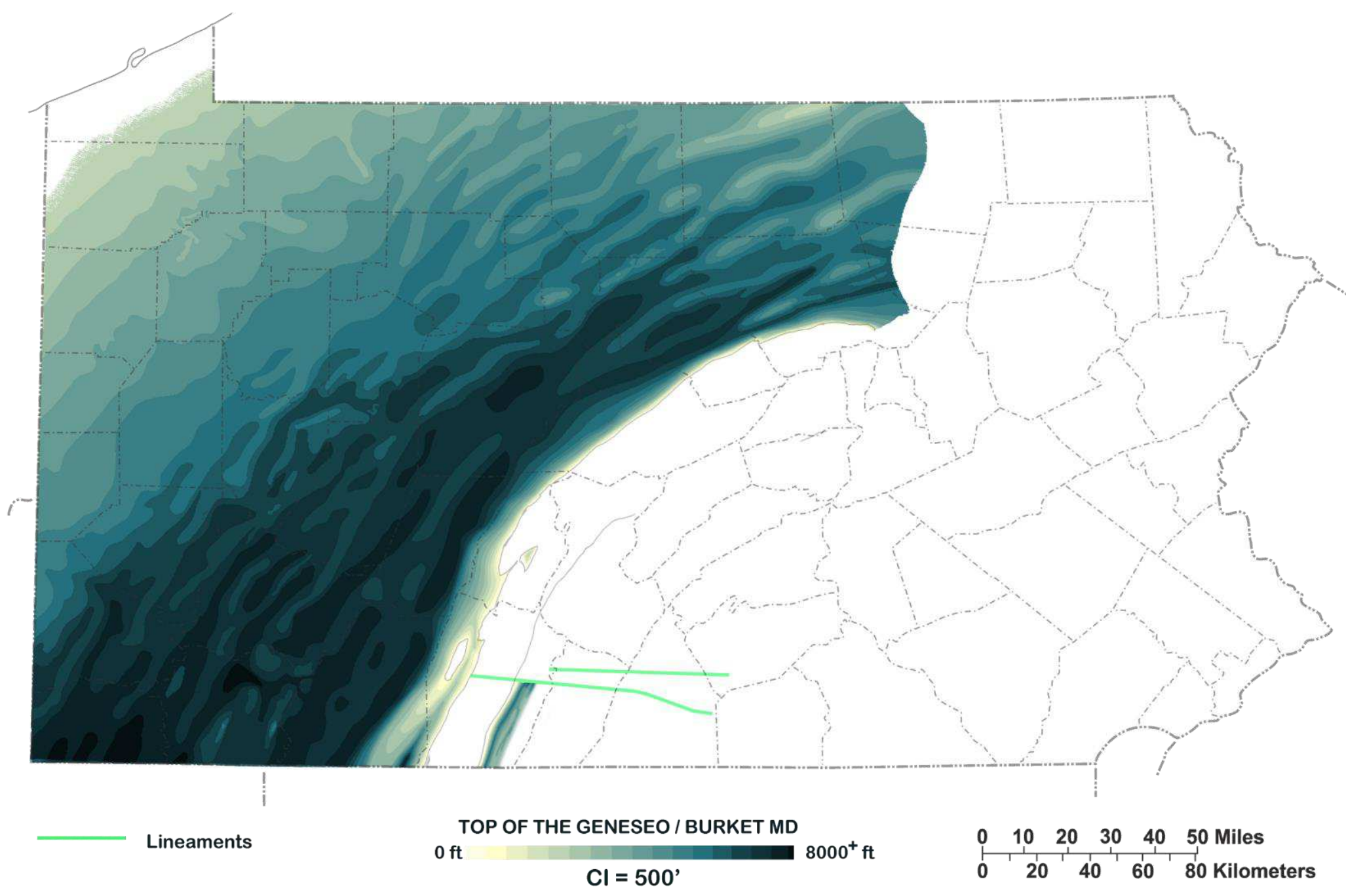




\section{Geneseo / Burket Major Lineaments}

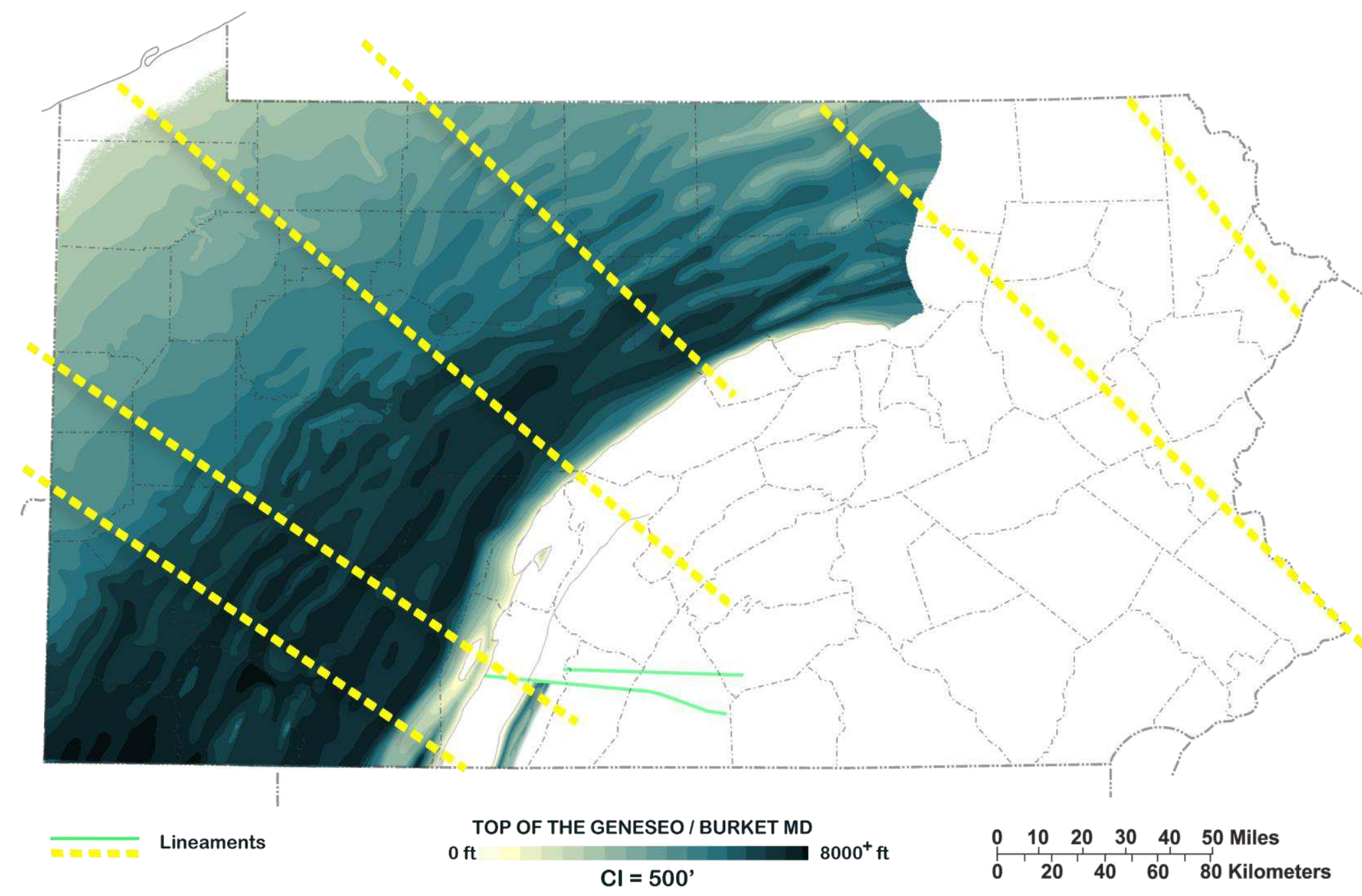




\section{Geneseo / Burket MD Lineaments}

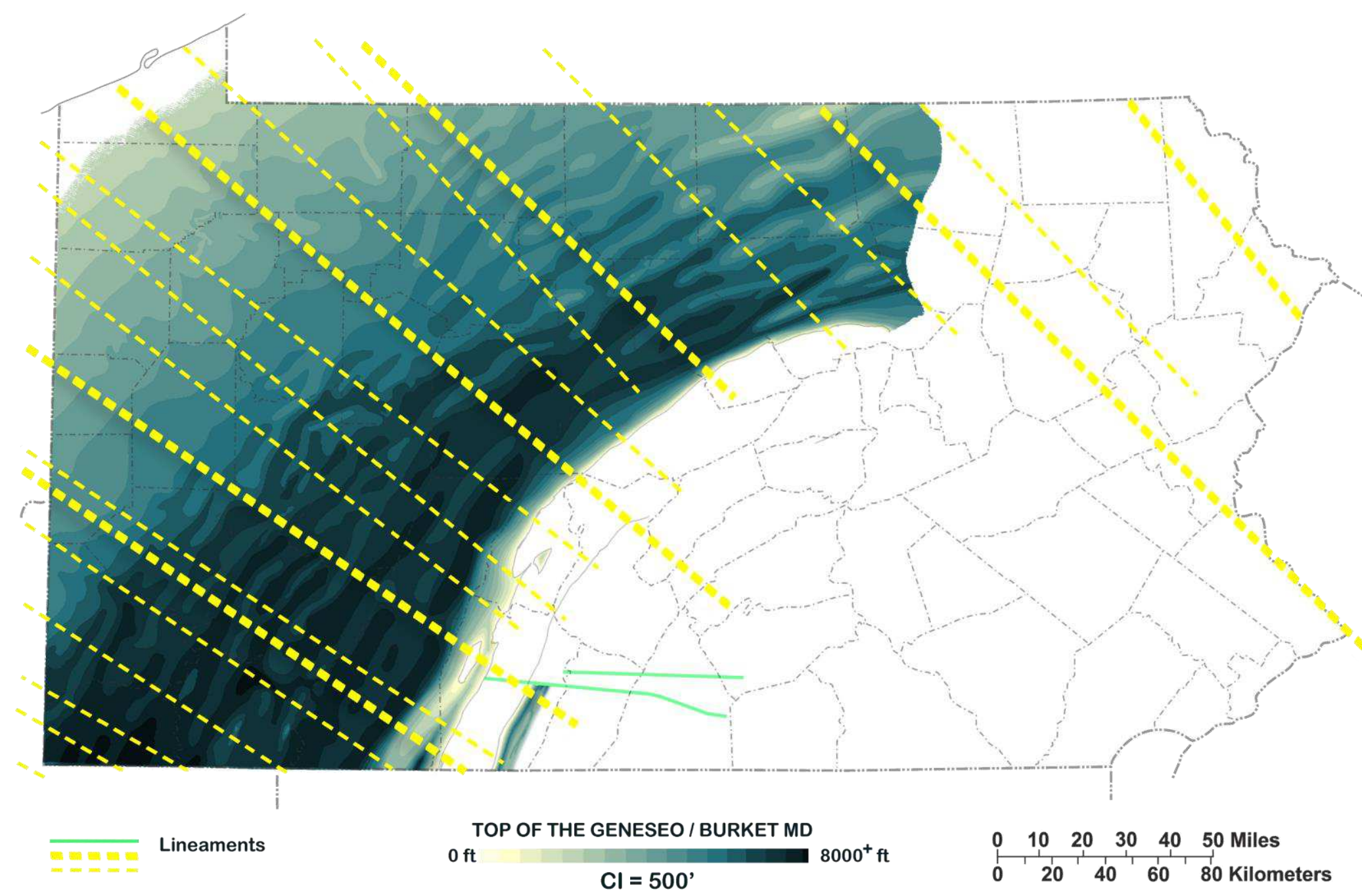




\section{Geneseo / Burket}

\section{Cross-section inset 1 along E-E'}

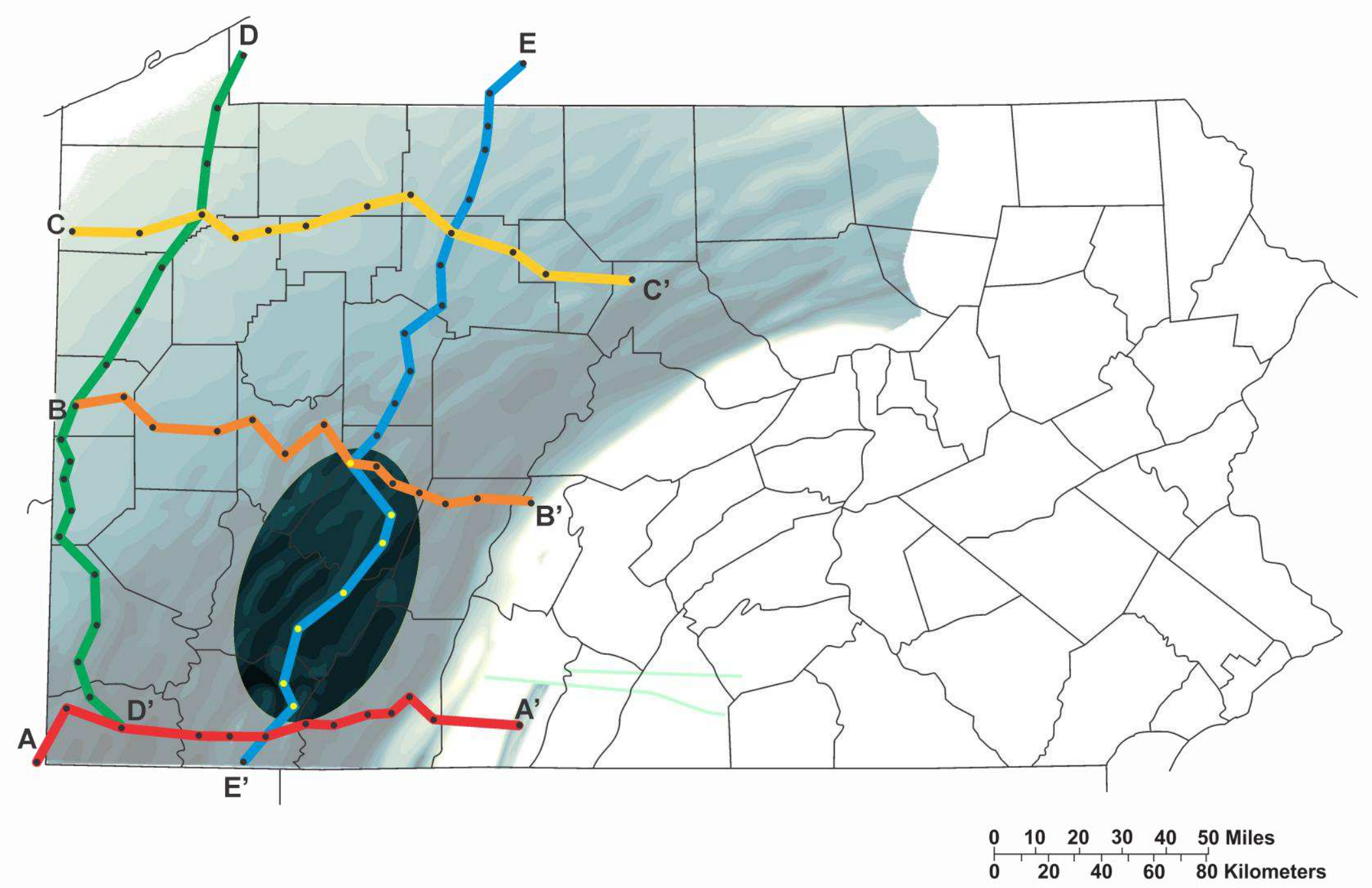




\section{Geneseo / Burket}

\section{Cross-section inset 1 along E-E'}

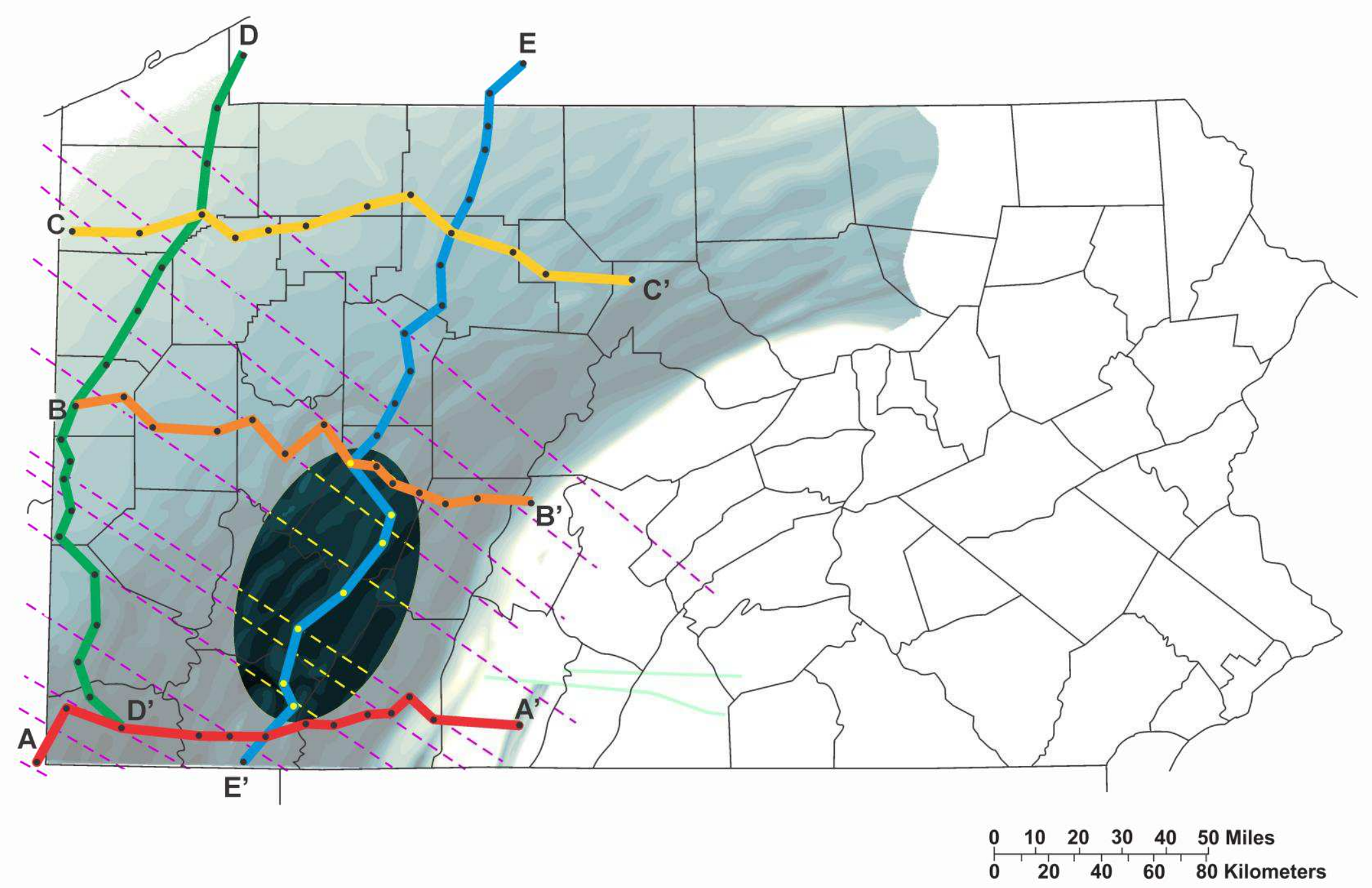




\section{Geneseo / Burket}

\section{Cross-section Inset 1 along E-E'}

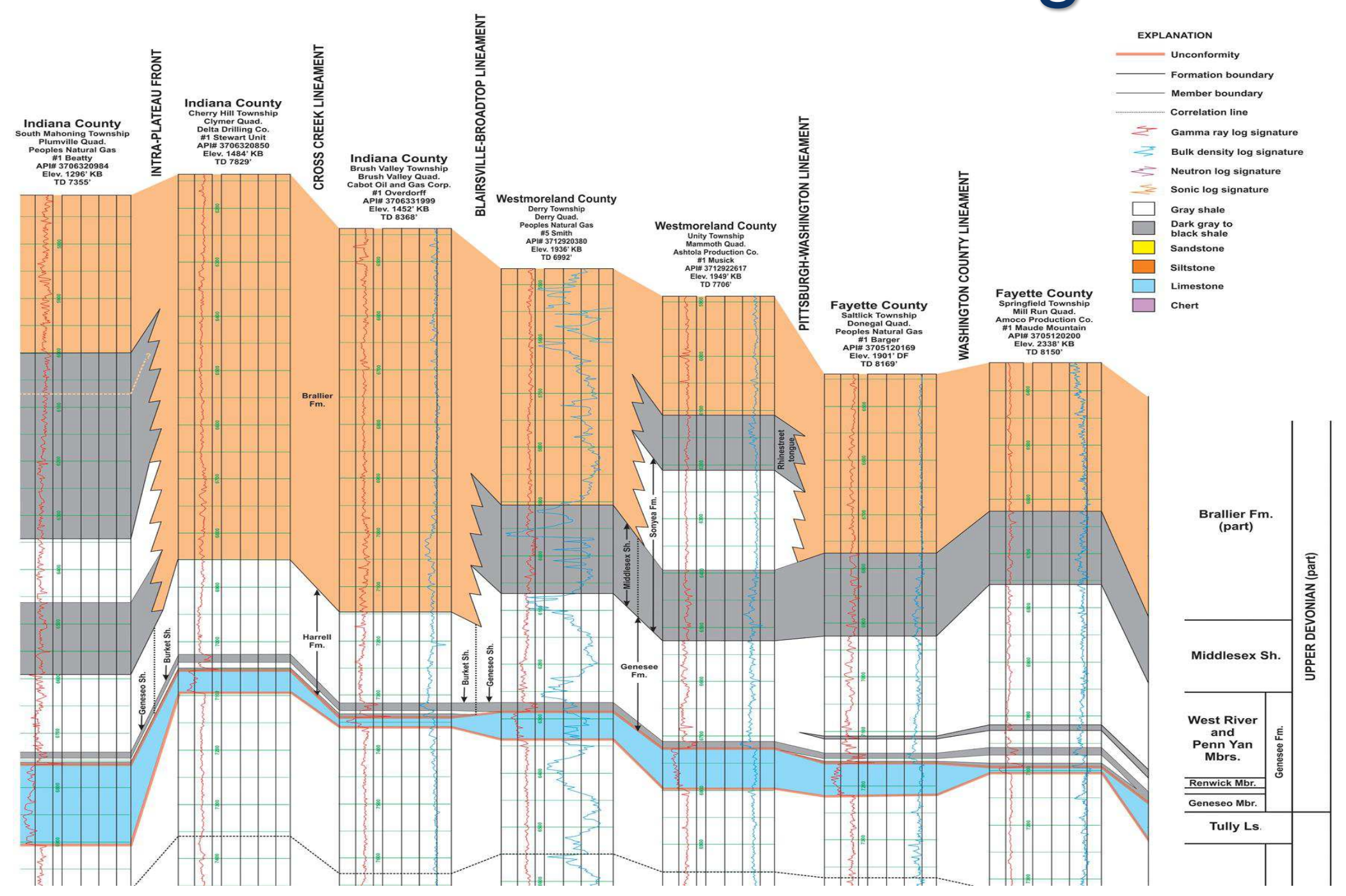




\section{Geneseo / Burket}

\section{Cross-section inset 2 along C-C"}

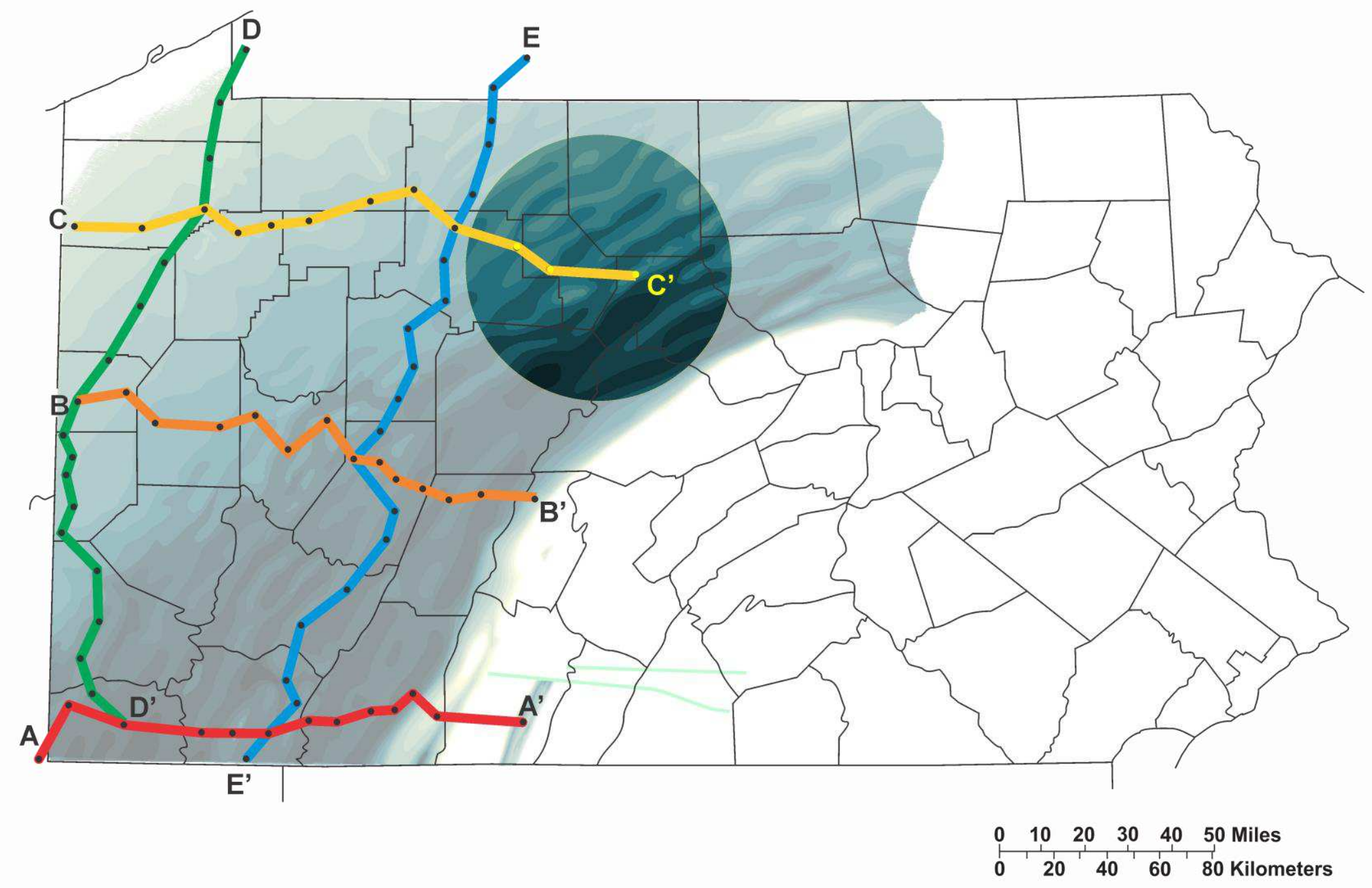




\section{Geneseo / Burket}

\section{Cross-section inset 2 along C-C"}

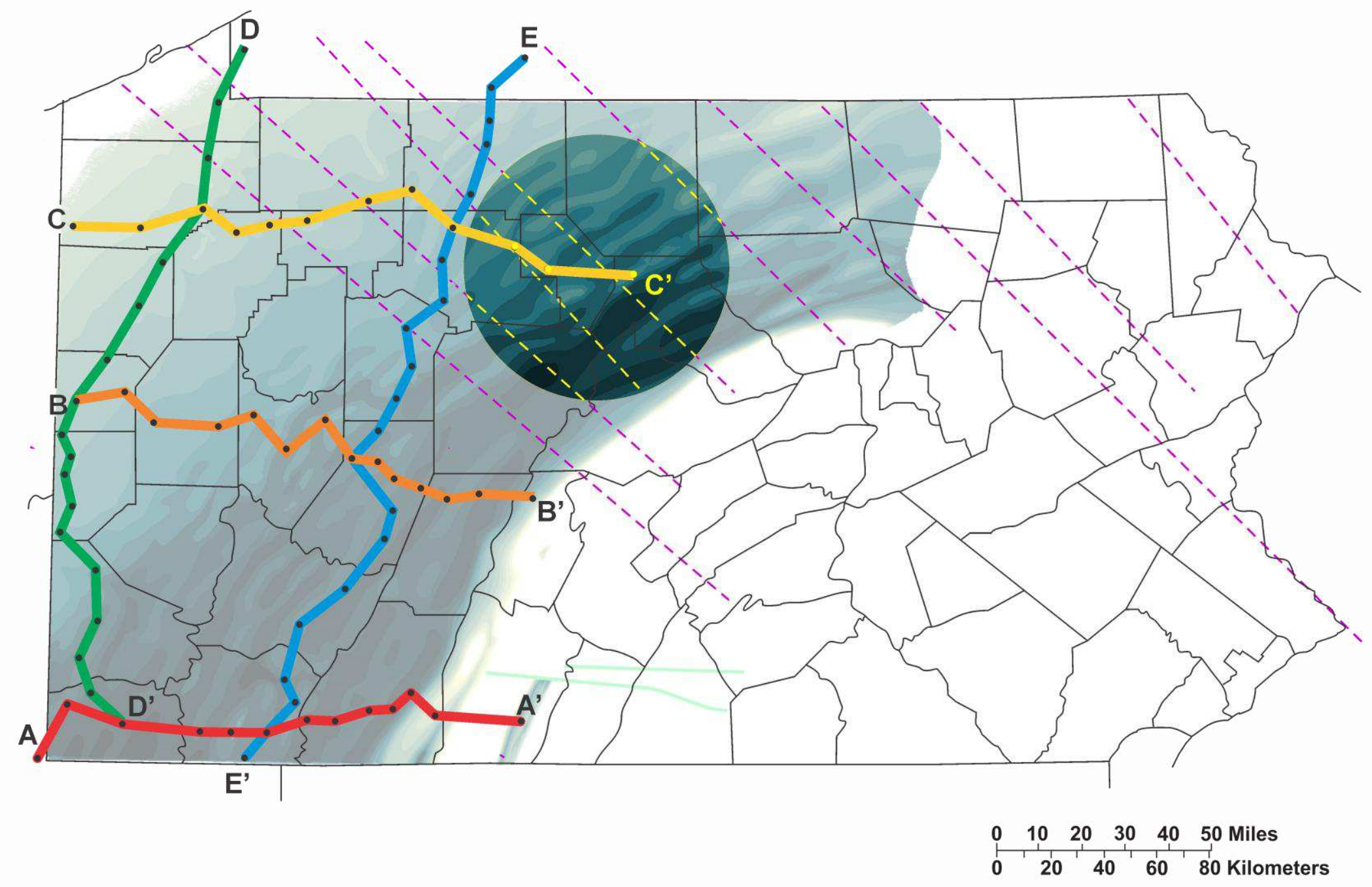




\title{
$C^{\prime}$
}

\section{Geneseo / Burket} Cross-section

\author{
inset 2 \\ along C-C"
}

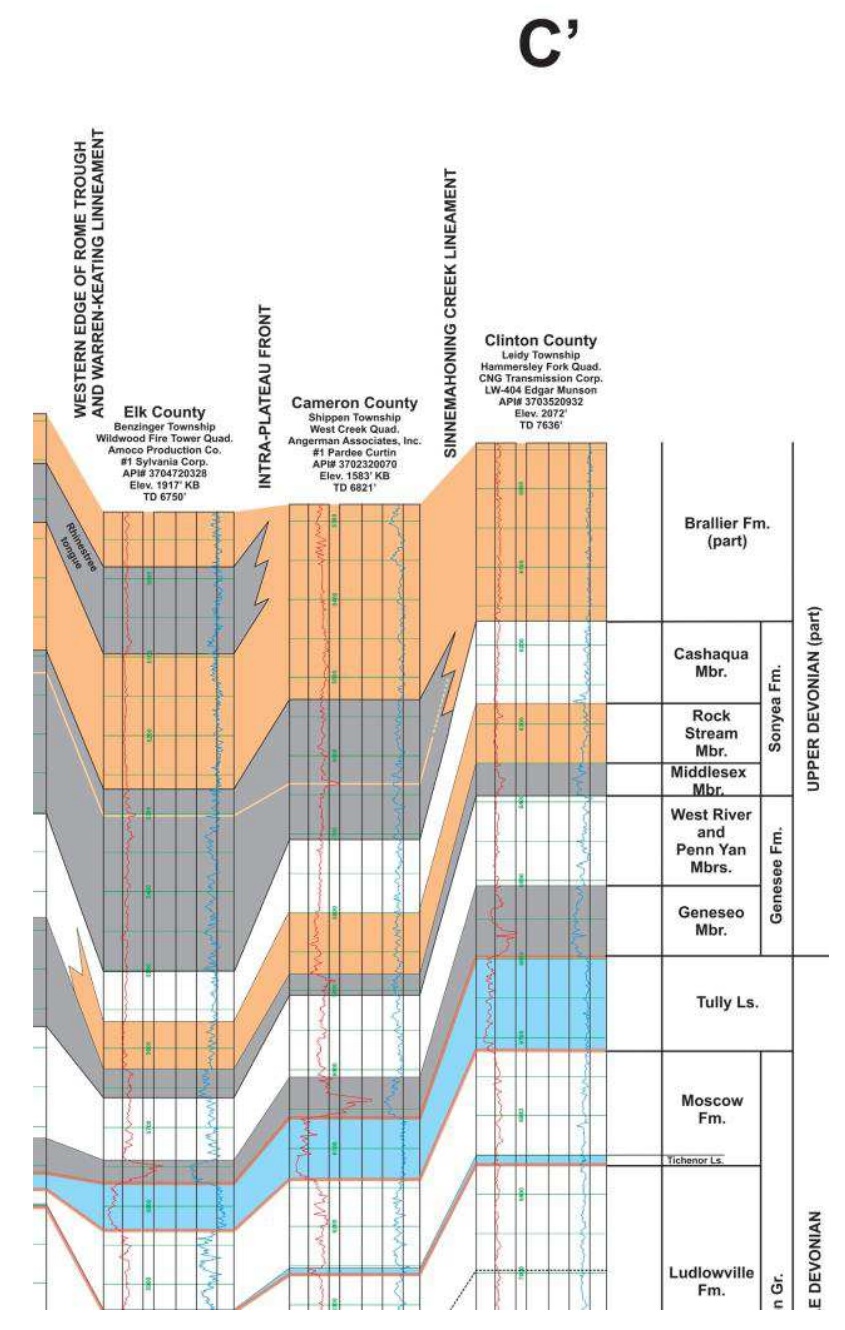




\section{Rhinestreet Shale}
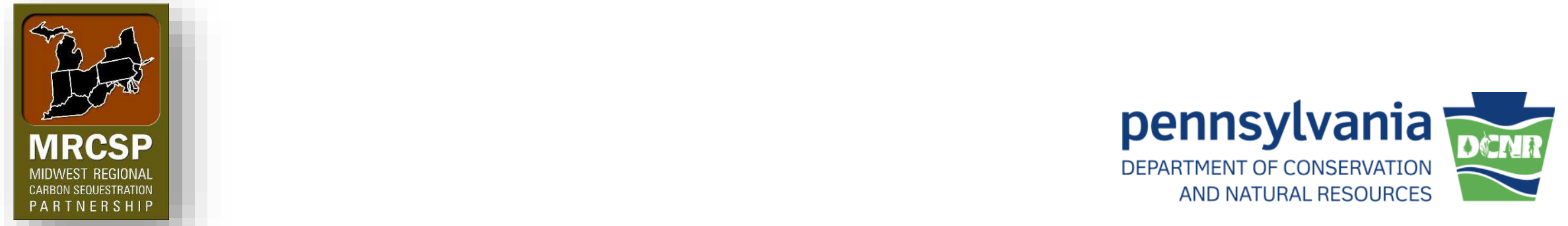


\section{Measured Depth to Top of Rhinestreet Shale}

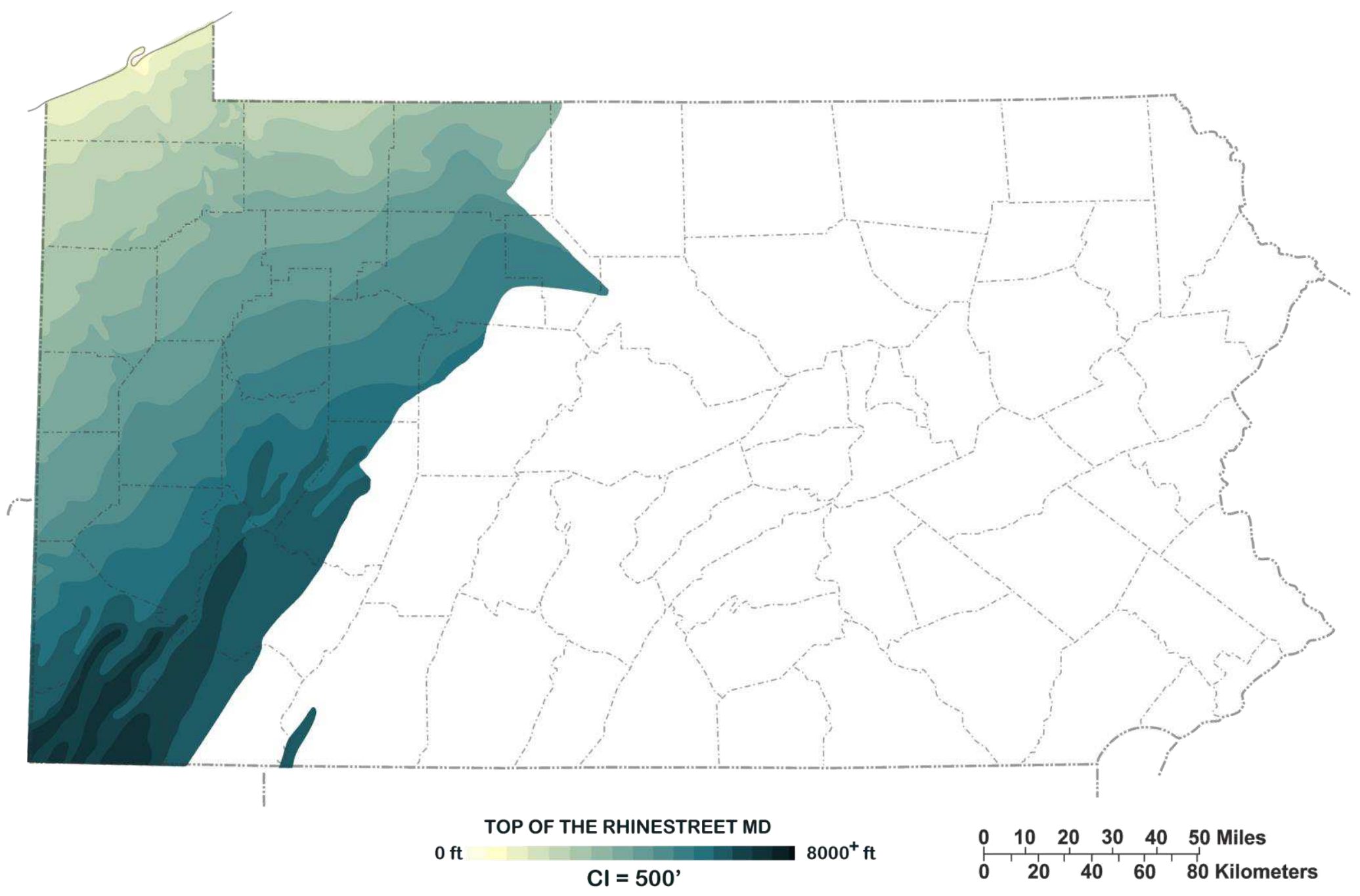




\section{Rhinestreet Shale Major Lineaments}

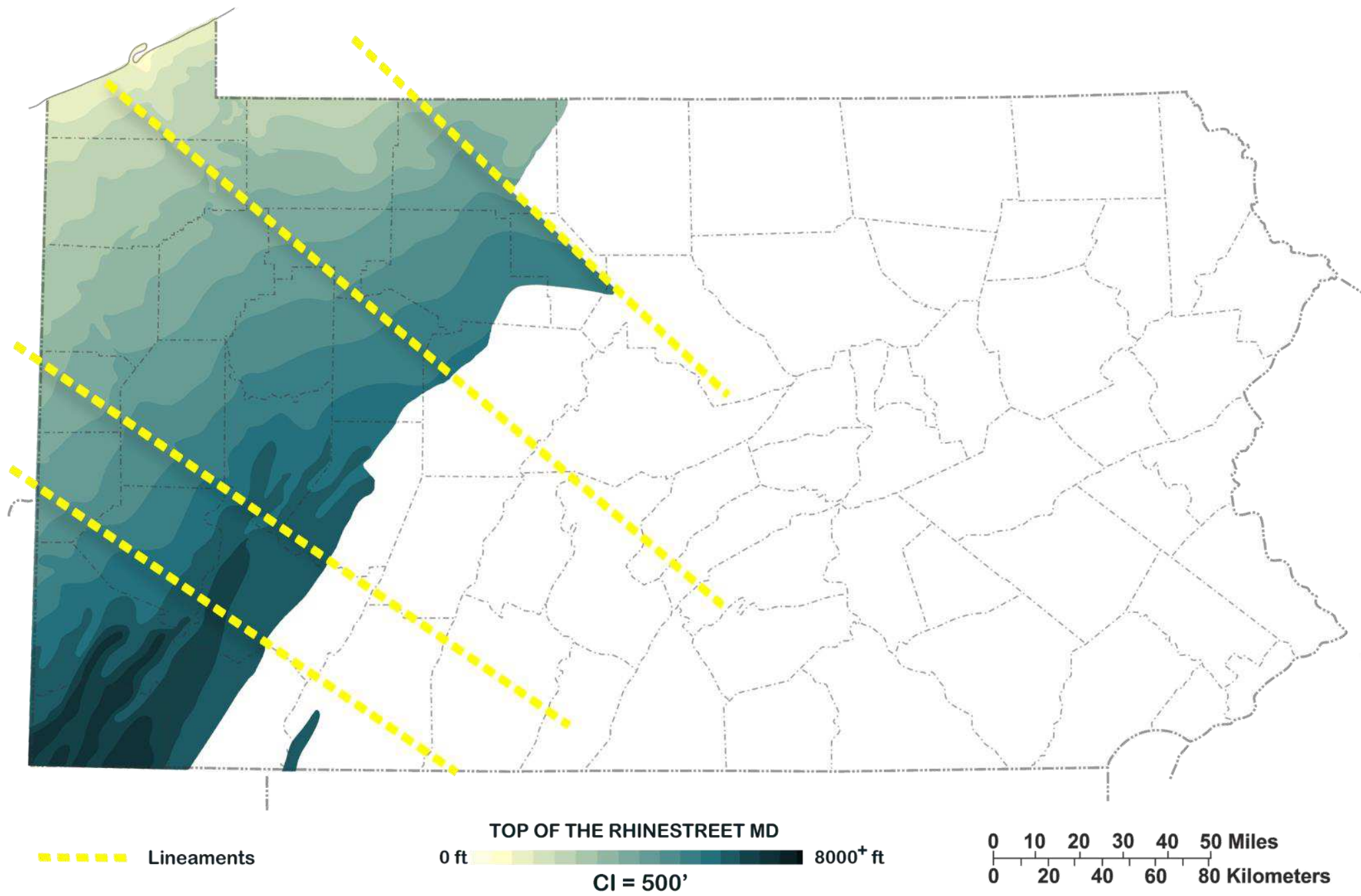




\section{Rhinestreet Shale MD Lineaments}

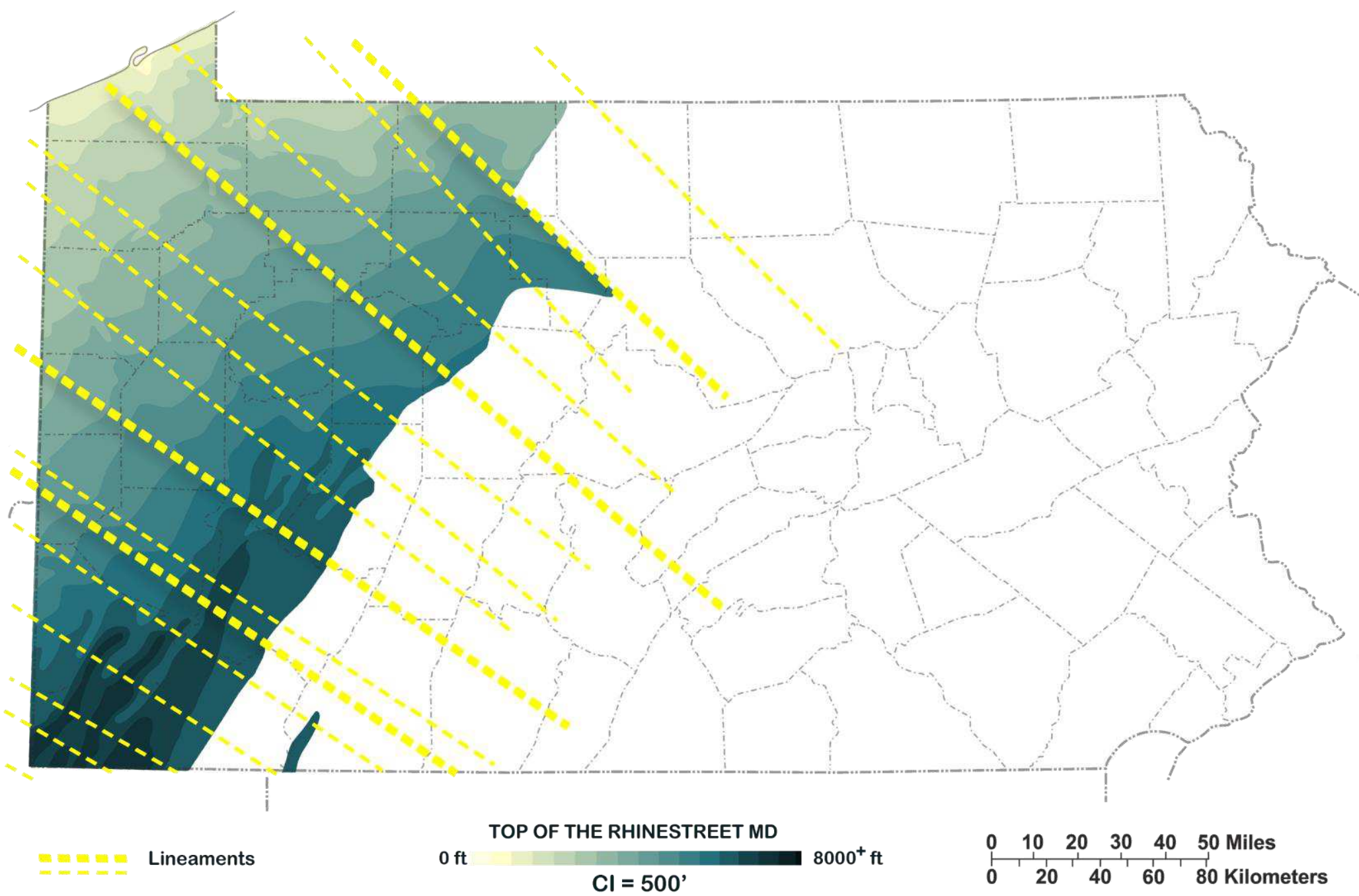




\section{Rhinestreet Shale}

\section{Cross-section inset D - D'}

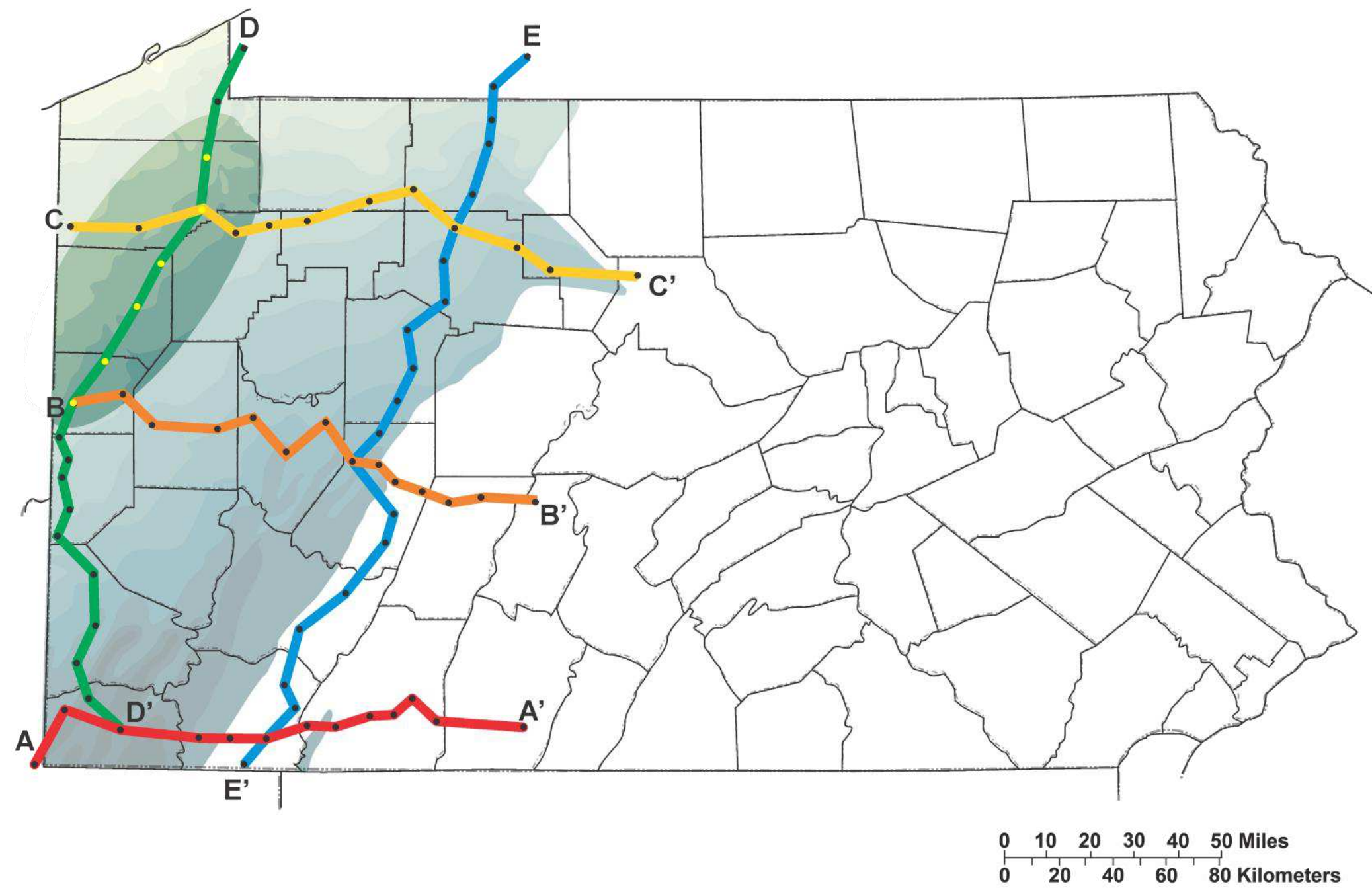




\section{Rhinestreet Shale}

\section{Cross-section inset D - D'}

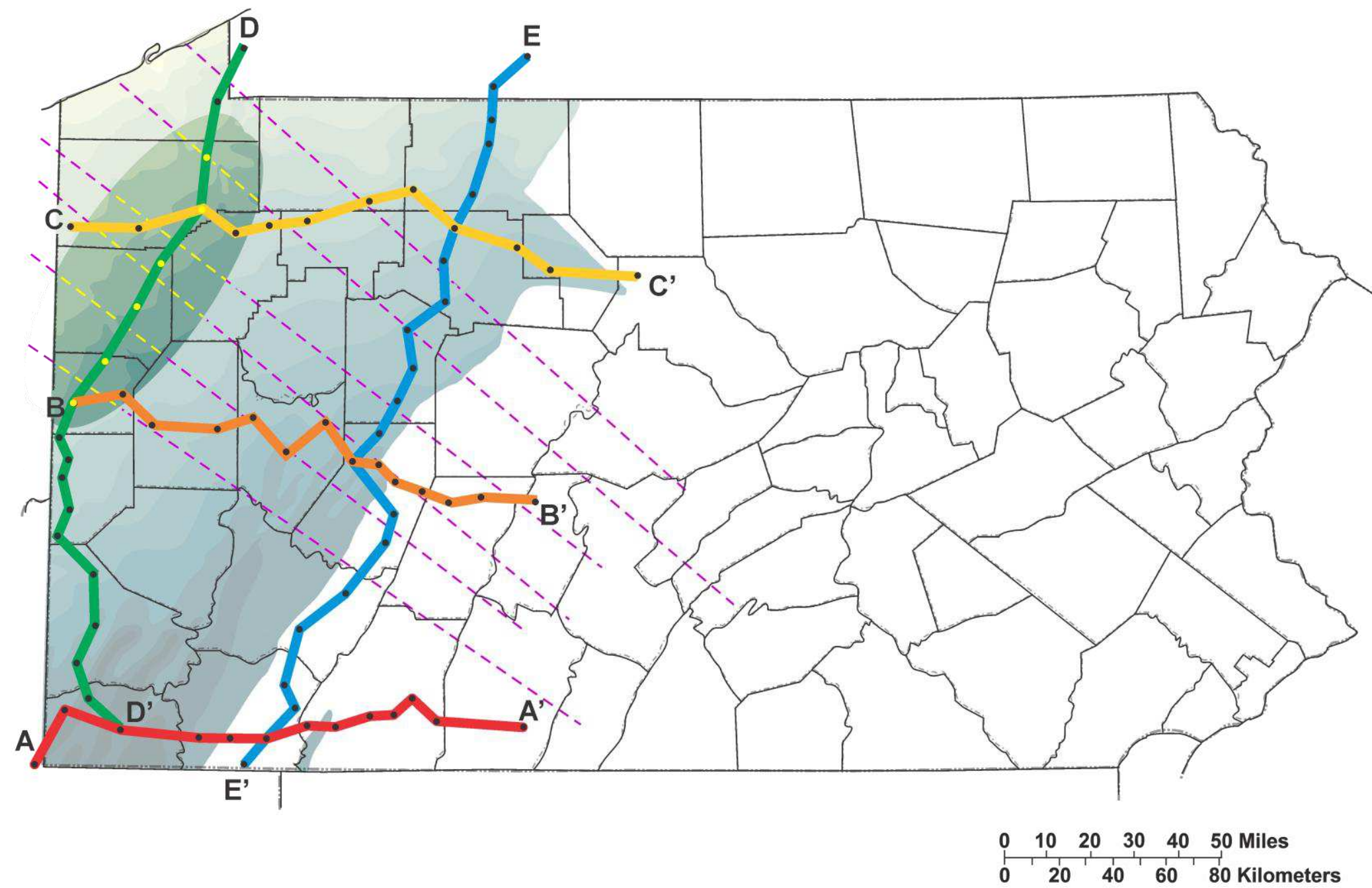




\section{Rhinestreet / Upper Devonian shales Cross-section Inset 1 along D-D'}

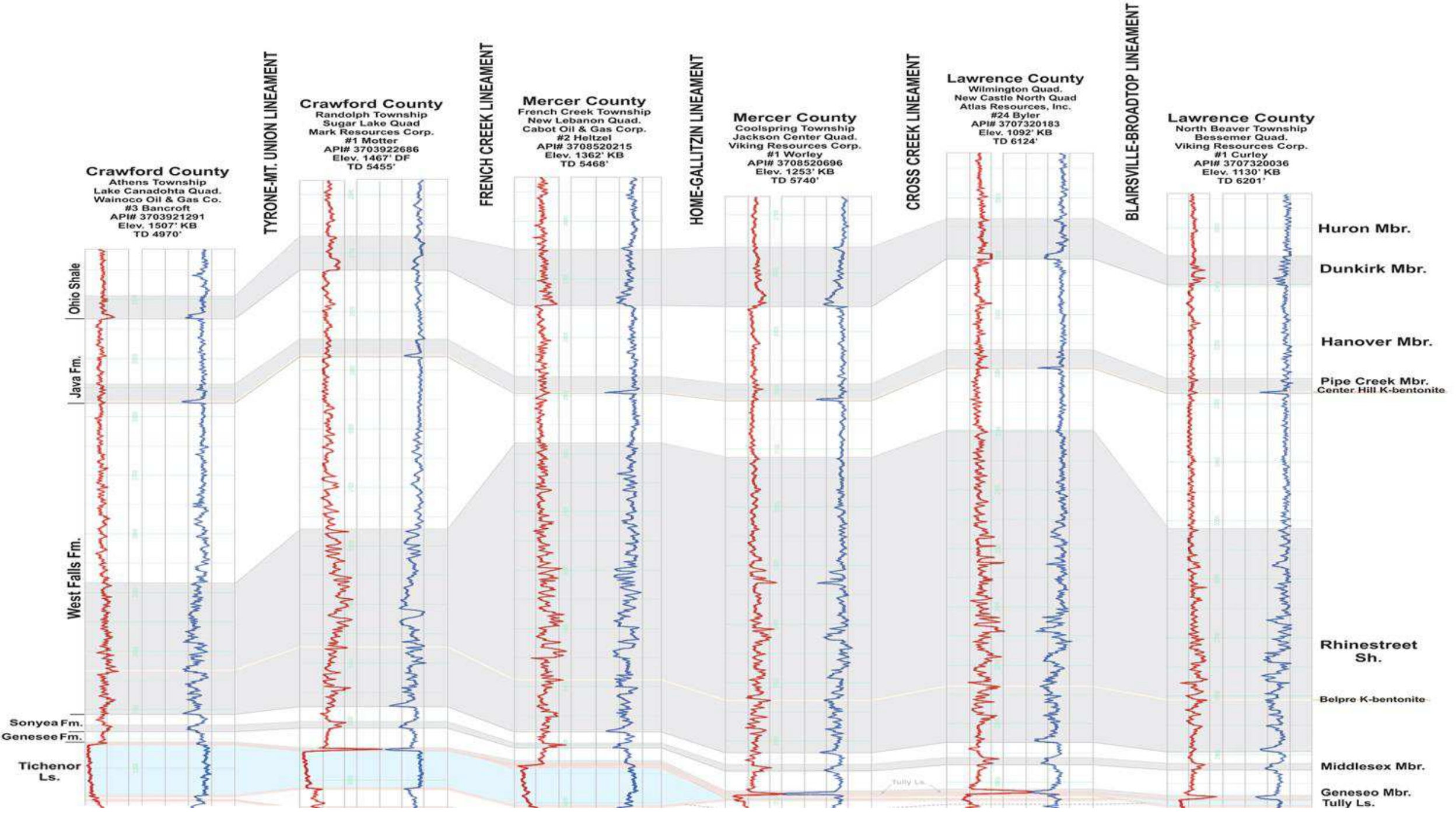




\section{Rhinestreet Shale}

\section{Cross-section inset $\mathrm{C}-\mathrm{C}^{\prime}$}

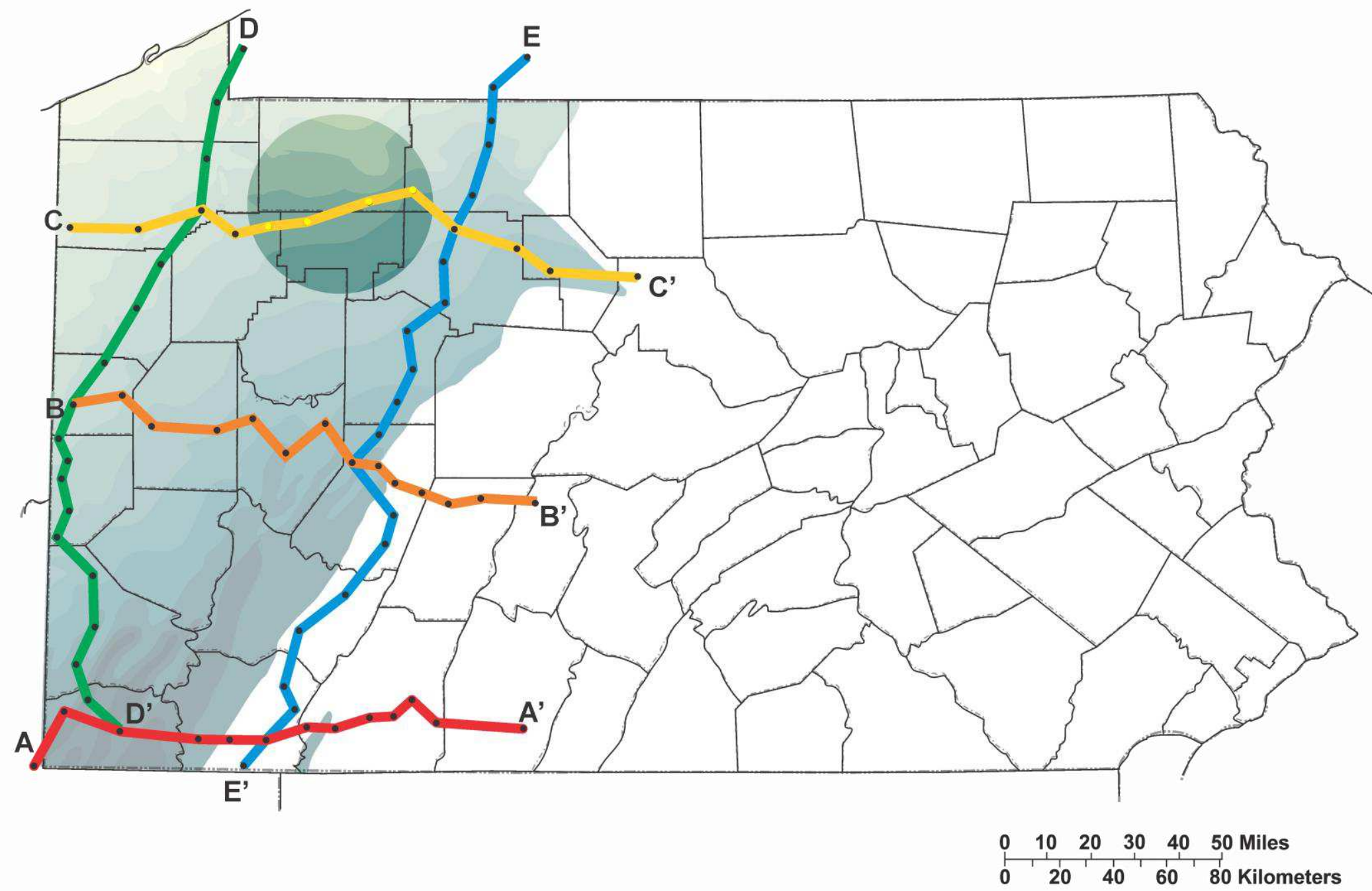




\section{Rhinestreet Shale}

\section{Cross-section inset $\mathrm{C}-\mathrm{C}^{\prime}$}

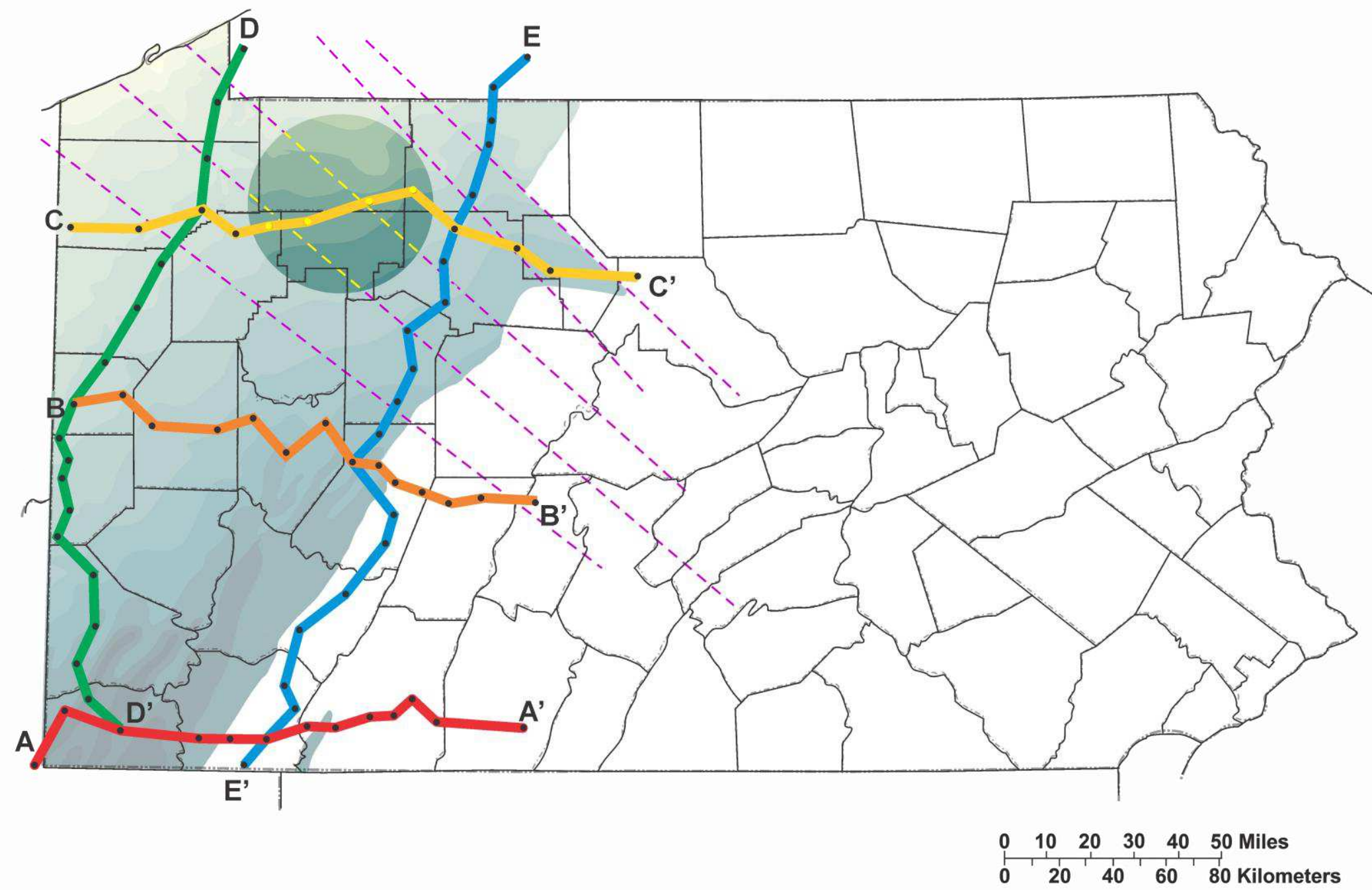




\section{Rhinestreet}

Upper Devonian shales

Cross-section inset 2

along C-C'

- Extending cross-

section eastward into northern tier.

- Lineaments influence deposition, pinch-outs and TOC.

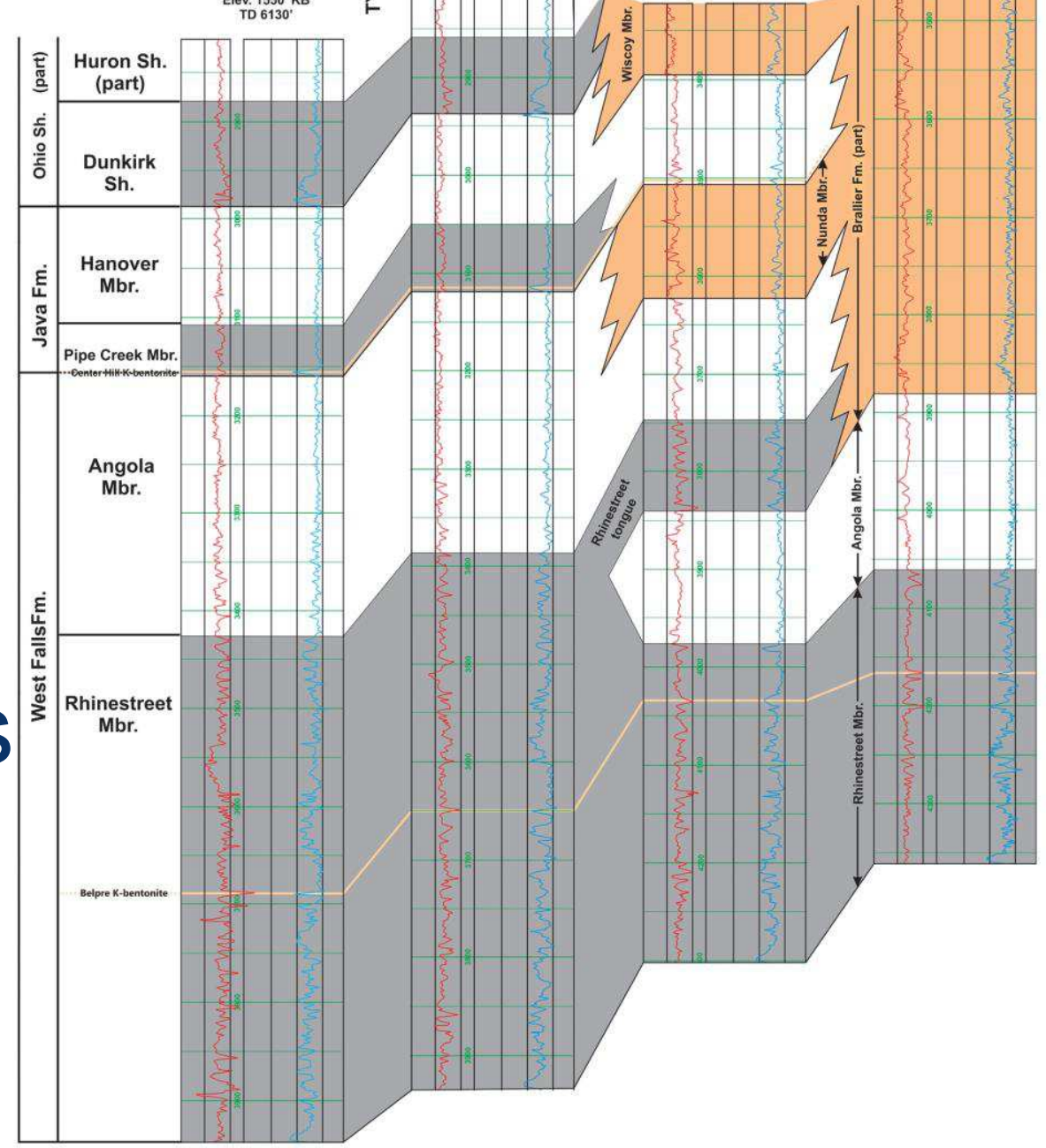




\section{Key Points}

- Builds on decades of shale research in PA

- 3,500 wells in 41 counties

- Revised shale lithology based on modern log suite (GR/Neutron/Density)

- Revising structure and isopach maps

- Lineaments control deposition, influence TOC and diagenesis

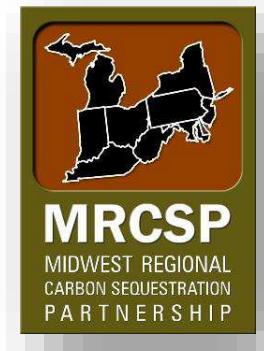




\title{
Please visit the MRCSP website to download our work:
}

\section{http://www.mrcsp.org/regional-validation}

\author{
Robin Anthony \\ Pennsylvania Geological Survey \\ (412) 442-4295 \\ robanthony@pa.gov
}

